\title{
Heyl and Hey2 Control the Spatial and Temporal Pattern of Mammalian Auditory Hair Cell Differentiation Downstream of Hedgehog Signaling
}

\author{
Ana Benito-Gonzalez ${ }^{1,2}$ and Angelika Doetzlhofer ${ }^{1,2}$ \\ ${ }^{1}$ Solomon H. Snyder Department of Neuroscience, Johns Hopkins University, School of Medicine, Baltimore, Maryland 21205, and ${ }^{2}$ Center for Sensory \\ Biology, Johns Hopkins University, School of Medicine, Baltimore, Maryland 21205
}

\begin{abstract}
Mechano-sensory hair cells (HCs), housed in the inner ear cochlea, are critical for the perception of sound. In the mammalian cochlea, differentiation of HCs occurs in a striking basal-to-apical and medial-to-lateral gradient, which is thought to ensure correct patterning and proper function of the auditory sensory epithelium. Recent studies have revealed that Hedgehog signaling opposes HC differentiation and is critical for the establishment of the graded pattern of auditory HC differentiation. However, how Hedgehog signaling interferes with HC differentiation is unknown. Here, we provide evidence that in the murine cochlea, Heyl and Hey 2 control the spatiotemporal pattern of HC differentiation downstream of Hedgehog signaling. It has been recently shown that HEY1 and HEY2, two highly redundant HES-related transcriptional repressors, are highly expressed in supporting cell (SC) and HC progenitors (prosensory cells), but their prosensory function remained untested. Using a conditional double knock-out strategy, we demonstrate that prosensory cells form and proliferate properly in the absence of $\mathrm{Hey} 1$ and $\mathrm{Hey} 2$ but differentiate prematurely because of precocious upregulation of the pro- $\mathrm{HC}$ factor Atoh1. Moreover, we demonstrate that prosensory-specific expression of Heyl and Hey2 and its subsequent graded downregulation is controlled by Hedgehog signaling in a largely FGFR-dependent manner. In summary, our study reveals a critical role for Heyl and Hey 2 in prosensory cell maintenance and identifies Hedgehog signaling as a novel upstream regulator of their prosensory function in the mammalian cochlea. The regulatory mechanism described here might be a broadly applied mechanism for controlling progenitor behavior in the central and peripheral nervous system.
\end{abstract}

Key words: Atoh1; hair cells; Hedgehog signaling; Hey1; Hey2; inner ear cochlea

\section{Introduction}

Auditory hair cells (HCs) and their surrounding supporting cells (SCs) derive from a common pool of postmitotic prosensory cells within the developing cochlear duct (Chen and Segil, 1999). Atoh1, which encodes for a basic helix-loop-helix (bHLH) transcriptional activator, is necessary for the generation of inner ear HCs (Bermingham et al., 1999) and is among the earliest known markers of auditory HCs (Chen et al., 2002b; Cai et al., 2013). Unique to the mammalian cochlea, ATOH1-mediated HC differentiation follows a distinct basal-to-apical gradient, whereby HCs located near the cochlear base differentiate first and the most apically located HCs differentiate last. In addition to the steep

Received April 11, 2014; revised July 25, 2014; accepted Aug. 9, 2014.

Author contributions: A.D. designed research; A.B.-G. performed research; A.B.-G. and A.D. analyzed data; A.B.-G. and A.D. wrote the paper.

This work was supported by Whitehall Foundation Grant 2010-05-81 to A.D. and National Institutes of Health Grant F32DC013477 to A.B.G. and DC 005211 (Sensory Mechanisms Research Core Center). We thank the Johns Hopkins University Center for Sensory Biology/Center for Hearing and Balance imaging facility, Manfred Gessler for the Hey1 floxed and Hey2 knock-out line, Jane Johnson for Atoh1/nGFP transgenic, and Andrew Groves for the Pax2-Cre BAC transgenic mouse line.

The authors declare no competing financial interests.

Correspondence should be addressed to Dr. Angelika Doetzlhofer, 855 North Wolfe Street, Rangos 433, Baltimore, MD 21205. E-mail: adoetzlhofer@jhmi.edu.

DOI:10.1523/JNEUROSCI.1494-14.2014

Copyright $\odot 2014$ the authors $\quad 0270-6474 / 14 / 3412865-12 \$ 15.00 / 0$ basal-to-apical differentiation gradient, a less steep gradient exits, with medially located inner HCs (IHCs) differentiating before laterally located outer HCs (OHCs) (Sher, 1971; Chen et al., $2002 \mathrm{~b})$. This unique pattern of differentiation is thought to ensure the precise arrangement of HCs, with one row of IHCs and three rows of OHCs spanning the length of the cochlear duct. Recent findings have shown that Hedgehog signaling negatively regulates ATOH1-mediated $\mathrm{HC}$ differentiation and is critical for the establishment of the basal-to-apical gradient of HC differentiation in the mammalian cochlea (Driver et al., 2008; Bok et al., 2013; Tateya et al., 2013). However, how Hedgehog signaling exerts its negative influence on Atohl expression and subsequently HC differentiation is unresolved. HES and HES-related HEY factors, which belong to the subfamily of bHLH transcriptional repressors, are known to interfere with bHLH activators at the transcriptional and post-transcriptional levels (Fischer and Gessler, 2007; Kageyama et al., 2008). In the CNS, gain-offunction studies have suggested that HEY and HES proteins cooperate with each other in suppressing bHLH activator-driven neuronal differentiation and in maintaining the neural stem cell fate (Ishibashi et al., 1994; Sakamoto et al., 2003). In the developing cochlea, two highly redundant Hey genes, Heyl and Hey2, are highly expressed in prosensory cells but are rapidly downregulated upon their differentiation and only persist in a subset of SC 
precursors (Hayashi et al., 2008b; Li et al., 2008; Doetzlhofer et al., 2009). In SC precursors, HEY1 and HEY2 cooperate with the coexpressed HES factors, HES1 and HES5, to repress a HCspecific gene program (Li et al., 2008; Tateya et al., 2011). Their functions in prosensory cells are unknown, but based on their responsiveness to Notch signaling, it has been proposed that Heyl and Hey2 function as Notch effectors in prosensory cell specification (Hayashi et al., 2008b). However, more recent findings suggest that in prosensory cells Hey1 and Hey2 expression is controlled by additional unidentified Notch-independent signaling mechanisms (Basch et al., 2011). Here, we show that Hey1 and Hey 2 are dispensable for prosensory cell specification and proliferation but are critical for maintaining prosensory cells undifferentiated. Moreover, we identify Hedgehog signaling as a critical upstream regulator of their prosensory-specific expression and graded downregulation during cochlear differentiation. Together, our findings indicate that Heyl and Hey2 control the spatial and temporal pattern of auditory HC differentiation downstream of Hedgehog signaling.

\section{Materials and Methods}

Mouse breeding and genotyping. Atoh $1 / n$ GFP transgenic mice (Lumpkin et al., 2003) were obtained from Jane Johnson (University of Texas Southwestern Medical Center, Dallas). Heyl floxed (Fischer et al., 2005) and Hey 2 knock-out (Gessler et al., 2002) mice were obtained from Manfred Gessler (University of Wuerzburg, Wuerzburg, Germany). Atoh1 floxed mice (Shroyer et al., 2007) were obtained from The Jackson Laboratory (Stock \#008681). Pax2-Cre BAC transgenic mice (Ohyama and Groves, 2004) were obtained from Andrew Groves (Baylor College, Houston). Mice were genotyped by PCR, and genotyping primers are available upon request. Hey 1 floxed and Hey2 knock-out and Pax2-Cre $\mathrm{tg} /+$ mice were used to produce Hey1-Hey2 double mutants (Pax2-Cre

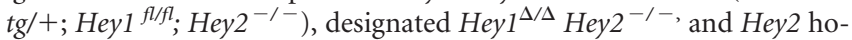
mozygous (Hey1 $\left.{ }^{f l / f l} H_{e y 2}{ }^{-/-}\right)$and Hey2 heterozygous mutant (Hey $1^{f l / f l}$ Hey $2^{-/+}$) littermates were used as experimental controls. Atoh1 floxed and Pax2-Cre tg/+ mice were used to generate Atoh1 mutant mice (Pax2Cre tg/+;Atoh $\left.1^{\mathrm{fl} / \mathrm{fl}}\right)$, designated Atoh $1^{\Delta / \Delta}$. These mice were maintained on a C57BL/6; CD-1 mixed background. Mice of both sexes were used in this study. Embryonic development was considered as E0.5 on the day a mating plug was observed. The day of birth was considered P0. All experiments and procedures were approved by the Johns Hopkins University Institutional Animal Care and Use Committees protocol, and all experiments and procedures adhere to National Institutes of Healthapproved standards.

Tissue harvest and processing. Embryos and early postnatal pups were staged using the EMAP eMouse Atlas Project (http://www.emouseatlas. org) Theiler staging criteria. Inner ear cochleae were collected in Hanks buffer (Invitrogen). To free the cochlear epithelial duct from surrounding tissue, dispase $(1 \mathrm{mg} / \mathrm{ml}$; Invitrogen) and collagenase (1 $\mathrm{mg} / \mathrm{ml}$; Worthington) mediated digest was used as previously described (Doetzlhofer et al., 2009). To prevent overdigestion, tissue was refixed after enzyme digestion with $4 \%$ para-formaldehyde (PFA). To expose the auditory sensory epithelium (Stage P0-P4), the cochlear capsule, spiral ganglion, and Reissner's membrane were removed, and the remaining tissue (cochlear surface preparation) was briefly fixed in $4 \%$ PFA. To obtain cochlear sections, whole heads (Stage E13.5-E15.5) or isolated inner ears (Stage P0-P4) were fixed in $4 \%$ PFA in PBS, cryoprotected using $30 \%$ sucrose in PBS, and embedded in OCT (Sakura Finetek) for cryosectioning.

Histochemistry and in situ hybridization (ISH). Immunostaining was performed as described previously (Doetzlhofer et al., 2009). Primary antibodies used were anti-Myosin VI (1:500, Proteus), anti-SOX2 (1:500, Santa Cruz Biotechnology), and anti-p75 (1:1000, EMD Millipore). Cell nuclei were fluorescently labeled with Hoechst-33258 dye (Sigma). Actin filaments were labeled with AlexaFluor (488 or 546) conjugated phalloidin (1:1000, Invitrogen). AlexaFluor (488 or 546) labeled secondary antibodies (1:1000, Invitrogen) were used. For ISH, pBluescript II (Strat- agene) and pGem-T easy (Promega) vectors containing full-length mouse Atoh1, Sox2, Hey1, and Hey2 cDNA were used as templates to synthesize digoxigenin-labeled antisense RNA probes according to the manufacturer's specifications (Roche). The ISH procedure was modified from a protocol from Domingos Henrique (Henrique et al., 1995).

Organotypic cochlear culture. E13.0-E13.5 embryos were screened for Atoh1/nGFP expression and staged (see Tissue harvest and processing). Embryos of inappropriate stage and nontransgenic embryos were discarded. Atoh1/nGFP transgenic inner ear cochleae were harvested in Hanks media (Invitrogen), and collagenase/dispase enzyme digest was used to free the cochlear duct from the surrounding mesenchyme. Remaining tissue, including the cochlear epithelial duct, the vestibular sacculus, and the innervating spiral ganglion, was placed onto filter membranes (SPI Supplies, Structure Probe) and cultured in DMEM-12 (Invitrogen), 1\% FBS (Atlanta Biologicals), 5 ng/ml EGF (Sigma), 100 $\mathrm{U} / \mathrm{ml}$ penicillin-streptomycin (Sigma), and $1 \times$ B27 supplement (Invitrogen). All cultures were maintained in a $5 \% \mathrm{CO}_{2} / 20 \% \mathrm{O}_{2}$ humidified incubator. Hedgehog ligand SHH (R\&D Systems) was used at $50 \mathrm{~nm}$ final concentration. Hedgehog inhibitor cyclopamine-KAAD (EMD Millipore) was used at $5 \mu \mathrm{M}$ final concentration. FGFR inhibitor SU5402 (3-[(3-(2carboxyethyl)-4-methylpyrrol-2-yl) methylene]-2-indolinone, Tocris Bioscience) was used at $10 \mu \mathrm{m}$ final concentration. Stock solutions for SHH (5 $\mu \mathrm{M}$ in PBS 0.1\% BSA), SU5402 (10 mM in DMSO), and cyclopamine-KAAD (5 $\mathrm{mm}$ in DMSO) were stored at $-80^{\circ} \mathrm{C}$. SHH, cyclopamine-KAAD, and SU5402 were added at plating, and control explants received $0.1 \%$ DMSO as vehicle control.

$X$-gal assay. To preserve $L a c Z$ encoded $\beta$-galactosidase activity, $\mathrm{Hey} 2^{\text {LacZ/+ }}$ cochlear explant cultures were fixed for 10 min with $2 \%$ PFA on ice. After washing in PBS, tissue was incubated at $35^{\circ} \mathrm{C}$ overnight in $\mathrm{X}$-gal reaction buffer containing $1 \mathrm{mg} / \mathrm{ml} \mathrm{X}$-gal (5-bromo-4-chloro-3indolyl-b-Dgalactopyranoside, Corning, Cellgro), $5 \mathrm{~mm} \mathrm{~K}_{3} \mathrm{Fe}(\mathrm{CN})_{6}$ (Sigma), $5 \mathrm{~mm} \mathrm{~K}_{4} \mathrm{Fe}(\mathrm{CN})_{6}$ (Sigma), and $2 \mathrm{~mm} \mathrm{MgCl}_{2}$. (Sigma) in PBS.

$R N A$ extraction and $q P C R$. Before RNA extraction, cochlear epithelia were isolated from cultured cochlear explants using dispase/collagenase treatment, and three to four cochlear epithelia were pooled per condition. RNeasy Micro kit (QIAGEN) was used to isolate total RNA, and mRNA was transcribed into cDNA using iScript kit (Bio-Rad). qPCR was performed with a SYBR Green kit (Invitrogen) and gene-specific primer sets on a StepOne Plus PCR Detection System (Applied Biosystems/ Invitrogen). Each PCR was performed in triplicate. Relative gene expression was analyzed by using the $\Delta \Delta \mathrm{CT}$ method (Schmittgen and Livak, 2008). The comparative Ct study feature of StepOne plus software (Applied Biosystems/Invitrogen) was used to aggregate biological replicate data. C-DNA from freshly isolated cochlear epithelia, Stage E15.5 was used as a calibrator, and the ribosomal gene Rpl19 was used as endogenous reference gene. The following primers were used for qPCR: Atoh1 forward, ATG CAC GGG CTG AAC CA; Atohl-R TCG TTG TTG AAG GAC GGG ATA; Sox2 forward, CTG TTT TTT CAT CCC AAT TGC A; Sox2 reverse, CGG AGA TCT GGC GGA GAA TA; Hey1 forward, CAC TGC AGG AGG GAA AGG TTA T; Heyl reverse, CCC CAA ACT CCG ATA GTC CAT; Hey2 forward, AAG CGC CCT TGT GAG GAA A; Hey2 reverse, TCG CTC CCC ACG TCG AT; Hes1 forward, GCT TCA GCG AGT GCA TGA AC; Hes1 reverse, CGG TGT TAA CGC CCT CAC A; Fgf20 forward, CAC GGG TCG CAG GTA TTT TG; Fgf20 reverse, CCT GGC ACC ATC TCT TGG A; Isl1 forward, CGG AGA GAC ATG ATG GTG GTT; Isl1 reverse, AGG GCG GCT GGT AAC TTT G; Id1 forward, GAA CGT CCT GCT CTA CGA CAT G; Id1 reverse, TGG GCA CCA GCT CCT TGA; Id 2 forward, AAG GTG ACC AAG ATG GAA ATC CT; Id2 reverse, CGA TCT GCA GGT CCA AGA TGT; Id3 forward, GAG CTC ACT CCG GAA CTT GTG; Id3 reverse, CGG GTC AGT GGC AAA AGC; Ptch1 forward, CTG GCT CTG ATG ACC GTT GA; Ptch1 reverse, GCA CTC AGC TTG ATC CCA ATG; Rpl19 forward, GGTCTGGTTGGATCCCAATG; Rpl19 reverse, CCCGGGAATGGACAGTCA.

Proliferation assay. EdU (5-ethynyl-2'-deoxyuridine, Invitrogen) was reconstituted in PBS and administered at $50 \mu \mathrm{g}$ per gram of body weight to time-mated pregnant dams by a single intraperitoneal injection. Click-iT AlexaFluor-488 or -546 Kit (Invitrogen) was used to detect incorporated EdU according to the manufacturer's specifications. EdU incorporation in prosensory cells, HCs, and SCs was quantified in co- 
chlear sections and cochlear surface preparations, which have been stained with a nuclear dye (Hoechst-33258) and immunostained for SOX2 and myosin VI (MYO6) to visualize prosensory cells, SCs, and HCs, respectively. Confocal images were assembled and analyzed in Photoshop CS3 (Adobe), and ImageJ software (National Institutes of Health) was used to measure the length of counted segments.

Quantification of basal to apical extent of HC differentiation. HC differentiation in E13.0-E13.5 Atoh1/nGFP transgenic cochlear explants was monitored over 48-h culture period, and green fluorescent images of native GFP expression were captured using fluorescent stereo-microscopy (Leica) every $12 \mathrm{~h}$. HC differentiation in E15.0 DKO and control cochlear tissue was analyzed in enzyme-purified cochlear epithelial preparations immunostained for HC marker MYO6. Fluorescent images were analyzed in Photoshop CS3 (Adobe), and lengths of Atoh1/nGFP-positive and MYO6-positive domains were measured using ImageJ software (National Institutes of Health).

Quantification of HCs and SCs. Cochlear surface preparations obtained from P0-P2 DKO (Heyl $\left.1^{\Delta / \Delta} \mathrm{Hey}^{-/-}\right)$pups and control littermates $\left(\mathrm{Hey} 2^{-{ }^{+}}\right.$and Hey2 $\left.2^{-{ }^{-}}\right)$were immunostained for MYO6 and SOX2. High-power confocal images of SC layer $\left(\mathrm{SOX}^{+}{ }^{+}\right.$) and $\mathrm{HC}$ layer $\left(\mathrm{MYO6}^{+}\right)$at defined apical-basal positions were used for HC and SC counts. Low-power fluorescent images of the HC layer were used to reconstruct the entire cochlear sensory epithelium. Images were assembled and analyzed in Photoshop CS3 (Adobe). ImageJ software (National Institutes of Health) was used to measure length of counted segments and total length.

Statistical analysis. Values are presented as mean \pm SEM; $n=$ biological replicates analyzed. Two-tailed Student's $t$ tests were used to determine the confidence interval. $p \leq 0.05$ were considered significant. $p$ values $>0.05$ were considered not significant.

\section{Results}

\section{Downregulation of Hey 1 and Hey2 during cochlear} differentiation occurs independently of Atoh1

Hey 1 and Hey 2 are highly expressed by prosensory cells in the undifferentiated cochlea. As differentiation progresses along the developing cochlear duct, their expression becomes restricted to distinct subtypes of SCs (Hayashi et al., 2008b; Li et al., 2008; Doetzlhofer et al., 2009). The mechanism responsible for the graded downregulation of Hey1 and Hey2 during cochlear differentiation is currently unknown. One possibility is that Heyl and Hey 2 downregulation is a result of $\mathrm{HC}$ differentiation. To examine the dynamics of Heyl and Hey 2 expression in prosensory cells and to address whether Hey1 and Hey2 downregulation depends on HC differentiation, Hey1, Hey2, and Atoh1 mRNA expression was analyzed in embryonic day 13.5 (E13.5) and E15.5 wild-type and E15.5 Atoh1 mutant cochlear tissue using RNA in situ hybridization (ISH) assays. ISH staining for Sox2 was used to mark the prosensory/sensory domain (bracket). Sox 2 encodes for a high-mobility group transcription factor, known to be highly expressed in prosensory cells and embryonic HCs and SCs (Kiernan et al., 2005). At E13.5, Hey1 and Hey2 were coexpressed with Sox2 in prosensory cells throughout the cochlear duct (Fig. $1 A, C, D$, bracket), whereas Atoh1 was beginning to be upregulated in prosensory cells at the base of the cochlea (Fig. $1 B$, bracket). $48 \mathrm{~h}$ later, at E15.5, Atoh1 was highly expressed in both IHCs (arrowhead) and OHCs (bar) in the cochlear base. In the cochlear mid-turn Atoh1 was highly expressed in IHCs and was beginning to be upregulated in future OHCs (Fig. $1 F$, arrowhead and bar). In the undifferentiated cochlear apex, Atoh1 was faintly expressed in future IHCs at the medial border of the prosensory domain (Fig. 1F, arrowhead, bracket). At E15.5, Hey1 and Hey2 were highly expressed in the Sox2-positive prosensory domain in the undifferentiated cochlear apex, but in the cochlear mid-turn Hey 1 and Hey2 expression domain narrowed to the undifferentiated $\mathrm{OHC}$ domain (Fig. $1 E, G, H$ ). In the cochlear base, which
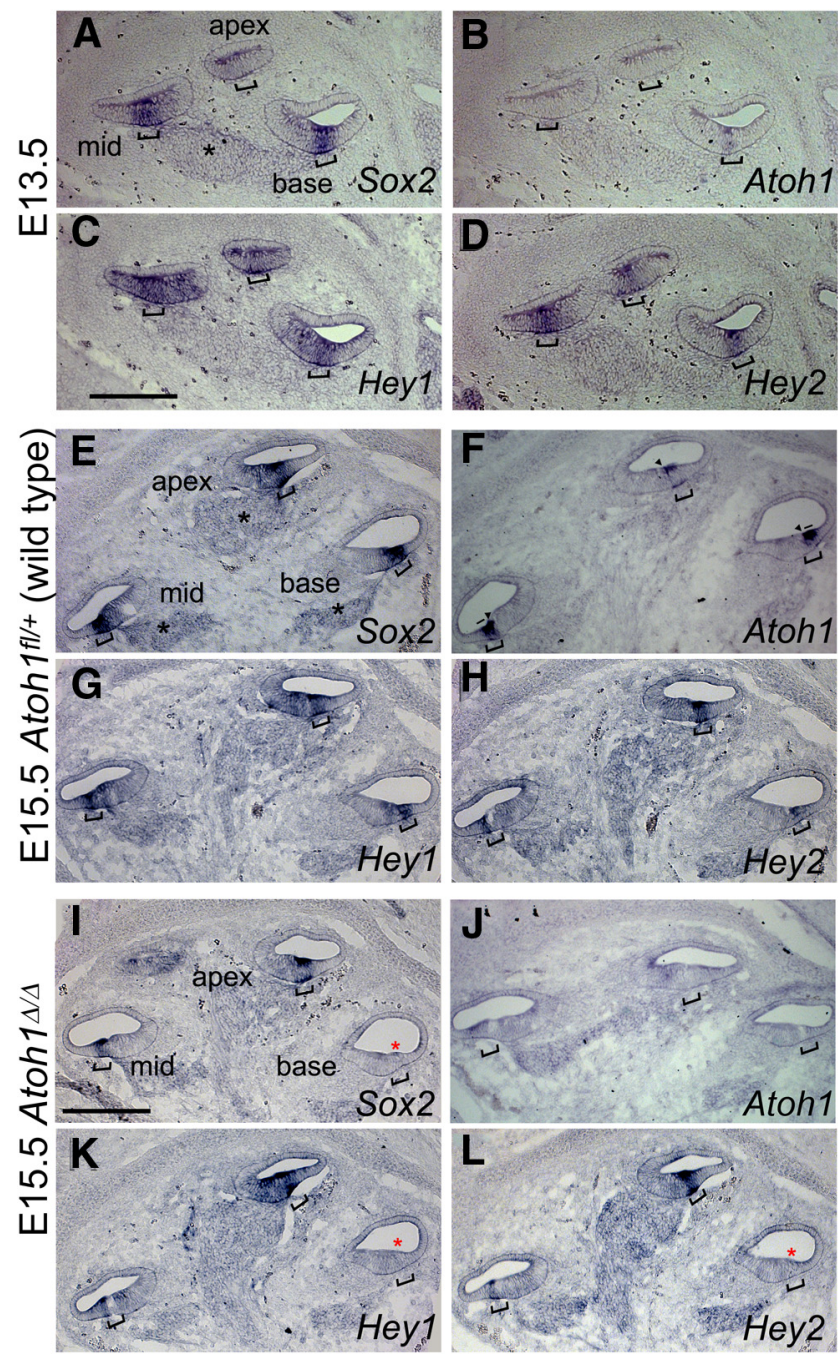

Figure 1. Hey 1 and Hey2 downregulation in prosensory cells occurs independently of Atoh1. $\boldsymbol{A}-\boldsymbol{D}$, Hey 1 and Hey2 transcripts are highly expressed in prosensory cells. At E13.5, Hey $1(\boldsymbol{C})$ and Hey2 $(\boldsymbol{D})$ are coexpressed with Sox2 ( $\boldsymbol{A}$ ) in the prosensory domain (bracket) and Atoh 1 ( $\boldsymbol{B})$ begins to be upregulated in the cochlear base. $A$, ${ }^{*}$ Sox2 expression in spiral ganglion neurons. Scale bar, $200 \mu \mathrm{m}$. $\boldsymbol{E}-\boldsymbol{L}$, Downregulation of Hey 1 and Hey 2 occurs in the absence of HC differentiation. In E15.5, Atoh $7^{\text {fl/++ }}$ (wild-type) cochlear tissue, basal-to-apical upregulation of Atoh $1(\boldsymbol{F})$ in IHCs (arrowhead) and $0 \mathrm{HCs}$ (bar) coincides with the basal-to-apical downregulation of Hey $1(\boldsymbol{G})$ and Hey2 $(\boldsymbol{H})$ in Sox2-positive $\mathrm{HC}$ and SC precursors ( $\boldsymbol{E}$, bracket). $\boldsymbol{E}$, ${ }^{*}$ Sox2 expression in ganglion neurons. In E15.5, Atoh1 mutant $\left(A t o h 1^{\Delta / \Delta}\right)$ cochlear tissue initial downregulation of Hey $1(\boldsymbol{K})$ and Hey2 $(\boldsymbol{L})$ in Sox2-positive $\mathrm{HC}$ and $\mathrm{SC}$ precursors ( $\boldsymbol{I}$, bracket) occurs in the absence of Atoh1 (J). Red asterisks indicate degenerated sensory epithelia in the Atoh1 mutant cochlear base. Scale bars, $200 \mu \mathrm{m}$.

already contained Atoh1 expressing IHCs and OHCs, Heyl and Hey2 expression was confined to differentiating SC precursors (Fig. $1 F-H$ ). Previous studies showed that in the Atoh1 mutant cochlea, prosensory cells form and express Sox 2 and Hey 2 but fail to differentiate into HCs and SCs (Woods et al., 2004; Kiernan et al., 2005; Li et al., 2008). Consistent with these findings, prosensory-specific expression of Sox2, Heyl, and Hey 2 in the undifferentiated cochlear apex appeared to be unaffected by the loss of Atoh1 (Fig. 1I-L). Moreover, the initial downregulation of Hey 1 and Hey2 appeared to be equally unaffected by the loss of Atoh1. In the mid-turn of both the E15.5 wild-type (Fig. 1G,H) and Atoh1 mutant (Fig. $1 K, L$ ) cochleae, Heyl (Fig. $1 G, K$ ) and Hey2 (Fig. $1 H, L$ ) were downregulated in the IHC domain but continued to be weakly expressed in the $\mathrm{OHC}$ domain. However, 
in the Atoh1 mutant cochlear base, no Sox2, Hey1, or Hey2 expression was detected (Fig. 1I, K,L). Previous studies showed that basally located prosensory cells in the Atoh 1 mutant cochlea start to undergo apoptosis at E15.5 (Chen et al., 2002b; Cai et al., 2013). The observed loss of Sox2, Hey1, and Hey2 expression in the base of the Atoh 1 mutant cochlea is likely to be a secondary effect caused by the death of $\mathrm{HC}$ and SC precursors. Together, our data demonstrate that the initial downregulation of Heyl and Hey2 in prosensory cells occurs independently of Atohl, suggesting that Hey 1 and Hey2 might act upstream of Atoh1 and might negatively regulate Atohl induction during cochlear differentiation.

\section{Loss of Hey1 and Hey 2 results in premature onset of HC differentiation}

To determine the function of Heyl and Hey2 in the developing cochlea, Hey1-Hey 2 double mutant animals were generated. Conventional Hey1-Hey2 double-mutant animals die during early embryonic development because of severe vascular defects (Fischer et al., 2004). To prevent early embryonic lethality, a conditional knock-out strategy was applied in which, in a Hey2 mutant background (Gessler et al., 2002), Heyl floxed allele (Fischer et al., 2005) was ablated using the inner ear-specific Pax2Cre line (Ohyama and Groves, 2004). As previously reported, Heyl single knock-out mice show no obvious changes in both the number and organization of HCs or SCs (Hayashi et al., 2008b; Doetzlhofer et al., 2009). Hey2 single knock-out mice have, dependent on their strain background, either no defects in the number or organization of HCs or SCs (Hayashi et al., 2008b) or only very mild HC and SC patterning defects (Li et al., 2008; Doetzlhofer et al., 2009). Moreover, a previous study revealed no defects in prosensory cell proliferation or differentiation, allowing the use of Hey2 single mutants as experimental controls (Li et al., 2008). To confirm conditional Heyl deletion, qPCR experiments were performed on enzyme-purified cochlear epithelial ducts at Stage $\sim$ E13.5. Our analysis revealed that Heyl as well as Hey2 mRNA expression in the DKO cochlear epithelia was reduced 10 -fold compared with cochlear epithelia obtained from control littermates with one intact allele of Hey1 or Hey2, respectively. This suggests that our strategy successfully ablated Heyl and Hey 2 in the developing cochlea (Fig. $2 A$, red and white bar). Furthermore, our analysis revealed no significant difference in Sox 2 mRNA expression in DKO cochlear epithelia compared with control epithelia $\left(\mathrm{Hey} 1^{\Delta / \Delta} \mathrm{Hey2}^{-/+}, \mathrm{Heyl}^{+/+} \mathrm{Hey2}^{-/+}\right.$, $\mathrm{Hey1} \mathrm{I}^{+/+} \mathrm{Hey}^{-/-}$) (Fig. 2A, gray bar), suggesting that prosensory cell formation was not impacted by the loss of Heyl and Hey2. However, we observed that Atoh1 was noticeably higher expressed in DKO cochlear epithelia, compared with cochlear epithelia obtained from control littermates (Fig. 2A, dark gray bar). To address whether HC differentiation might have occurred prematurely in the absence of Heyl and Hey2, the pattern of Atoh1 transcript, ATOH1 activity, and HC-specific marker expression was analyzed in DKO embryos and their littermate controls ranging in stages from E14.0 to E15.5. At E14.5 in Hey2 ${ }^{-1-}$ control littermates, Atoh1 mRNA was only expressed in the cochlear base in a narrow band of cells, which will give rise to IHCs (Fig. 2B). However, in DKO embryos, Atoh1 mRNA was readily detected in both the IHC and OHC domains in the cochlear base and in the future IHC domain in the mid-turn of the cochlear duct (Fig. 2C). At E15.0 in control littermates, Atoh1 mRNA was expressed in both IHCs (arrowhead) and OHCs (bar) in the cochlear base and in IHCs in the cochlear mid-turn, but no Atoh1 expression was detected in the cochlear apex (Fig. 2D). However, in DKO animals, Atoh1 was readily detected in IHCs and OHCs
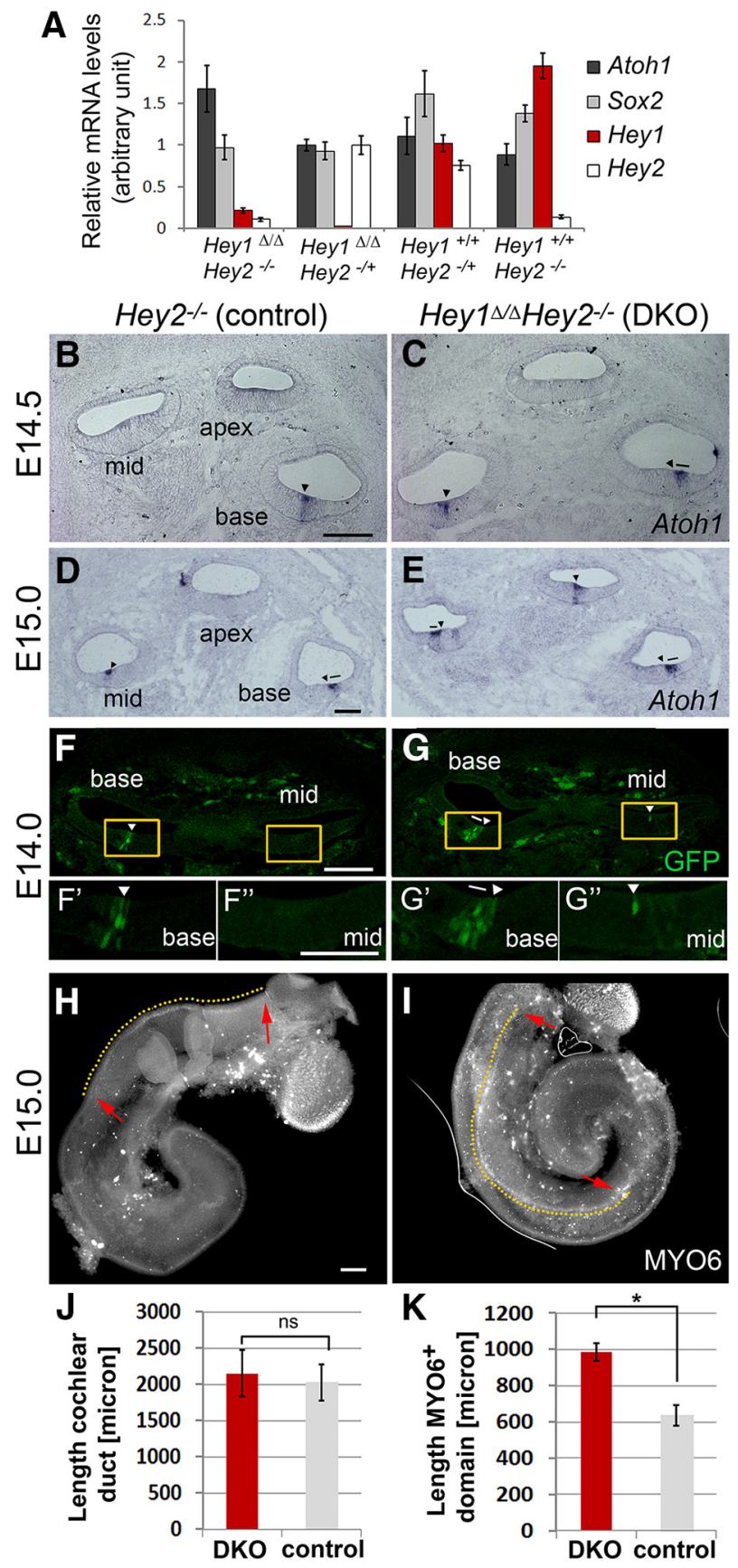

Figure 2. Loss of Hey 1 and Hey2 results in accelerated auditory HC differentiation. A, qPCR analysis of relative Atoh1, Sox2, Hey1, and Hey2 mRNA levels in Hey $7^{\Delta / \Delta}$ Hey2 ${ }^{-\prime-}$ (DKO) and control $\left(\mathrm{Hey} 1^{\Delta / \Delta} \mathrm{Hey2}{ }^{-/+}, \mathrm{Hey} 1^{+/+} \mathrm{Hey} 2^{-/+}\right.$and Hey $\left.1^{+/+} \mathrm{Hey} 2^{-/-}\right)$cochlear epithelia, Stage E13.5. Data are mean \pm SEM. $\boldsymbol{B}-\boldsymbol{E}$, ISH-based analysis of Atoh1 expression pattern in Hey2 $2^{-\prime-}$ (control) $(\boldsymbol{B}, \boldsymbol{D})$ and Hey $7^{\Delta / \Delta}$ Hey2 ${ }^{-\prime-}$ (DKO) $(\boldsymbol{C}, \boldsymbol{E})$ cochlear sections, Stage E14.5 $(\boldsymbol{B}, \boldsymbol{C})$ and Stage E15.0 (D, E). At both E14.5 and E15.0, Atoh1 expression extends further apically in DKO $(\boldsymbol{C}, \boldsymbol{E})$ than control $(\boldsymbol{B}, \boldsymbol{D})$ cochlear sections. Scale bar, $100 \mu \mathrm{m}$. $\boldsymbol{F}-\boldsymbol{G}^{\prime \prime}$, Low-power $(\boldsymbol{F}, \boldsymbol{G})$ and high-power $\left(\boldsymbol{F}^{\prime}, \boldsymbol{F}^{\prime \prime}, \boldsymbol{G}^{\prime}, \boldsymbol{G}^{\prime \prime}\right)$ confocal images of HC-specific Atoh1/nGFP reporter expression (green) in E14.0 Hey2 ${ }^{-/-}$(control; $\left.\boldsymbol{F}, \boldsymbol{F}^{\prime}, \boldsymbol{F}^{\prime \prime}\right)$ and E14.0 Hey $7^{\Delta / \Delta} \mathrm{Hey} 2^{-/-}\left(\right.$DKO; $\left.\boldsymbol{G}_{\mathbf{G}} \boldsymbol{G}^{\prime}, \boldsymbol{G}^{\prime \prime}\right)$ cochlear sections. $\boldsymbol{F}, \boldsymbol{G}$, Yellow boxes represent location of the high-power images $\left(\boldsymbol{F}^{\prime}, \boldsymbol{F}^{\prime \prime}, \boldsymbol{G}^{\prime}\right.$, $\left.\boldsymbol{G}^{\prime \prime}\right)$. Scale bar, $100 \mu \mathrm{m}$. $\boldsymbol{H}-\boldsymbol{I}$, Low-power images of E15.0 Hey2 ${ }^{-\prime-}(\boldsymbol{I})$ and E15.0 DKO $(\boldsymbol{H})$ cochlear epithelial ducts immunostained for myosin VI (MY06, white). Yellow dotted line indicates MY06-positive sensory domains; red arrows indicate beginning and end. Sale bar, 100 $\mu \mathrm{m} . J, \boldsymbol{K}$, Quantification of cochlear length and extent of HC differentiation in E15.0 Hey $7^{\Delta / \Delta}$ Hey2 $2^{-1-}$ (DKO) and Hey $2^{-1+}$ and Hey $2^{-1-}$ (control) littermates. Graphs represent cochlear duct length $(\boldsymbol{J})$ and length of MY06-positive sensory domain $(\boldsymbol{K})$ for control (gray bar) and DKO (red bar) cochlear ducts. Data are mean \pm SEM. $n=4$ or 5 cochlear explants from three independent experiments. ${ }^{*} p \leq 0.05$. n.S., Not significant. 
both in the cochlear base and cochlear mid-turn and Atoh1 mRNA started to be upregulated in the cochlear apex (Fig. 2E). To determine whether ATOH1 activity was also prematurely upregulated in the absence of Heyl and Hey2, we crossed the wellcharacterized HC-specific Atoh1/nGFP transgenic line into our Hey1-Hey2 double mutant line. Previous studies demonstrated that the Atoh1 enhancer used to drive GFP reporter expression is positively regulated by ATOH1 itself, making Atoh $1 / n$ GFP transgene expression a readout for ATOH1 activity (Helms et al., 2000; Lumpkin et al., 2003). At E13.5-E14.0, HC differentiation initiates at the cochlear mid-base, and in E14.0 Hey2 ${ }^{-1-}$ littermates (control) a narrow band of GFP-positive cells was only present in the cochlear base, representing future IHCs (Fig. $2 F, F^{\prime}$ ). No GFP-positive cells were observed further apically in the cochlear mid-turn (Fig. $2 F, F^{\prime \prime}$ ). However, in E14.0 DKO embryos, GFP was broadly expressed in future IHC and OHCs in the cochlear base (Fig. 2G, $G^{\prime}$ ), and GFP-positive cells were already observed in the cochlear mid-turn (Fig. $2 G, G^{\prime \prime}$ ). To quantify the basal-toapical extent of HC differentiation, cochlear epithelial preparations of Stage E15.0 DKO (Fig. 2I) and their Hey2 $2^{-/-}$control littermates (Fig. $2 \mathrm{H}$ ) were stained with the $\mathrm{HC}$ marker myosin VI (MYO6), and the length of the sensory domain containing MYO6-positive HCs was measured. As expected, both DKO and control cochlear epithelia were similar in length (Fig. $2 J$ ); however, HC differentiation, as judged by the basal-to-apical extent of HC-specific MYO6 expression, was more advanced in the Hey1-Hey2 double mutant (DKO) cochlea than in the Hey2 single mutant cochlea (control) (Fig. $2 K$ ). In summary, our data suggest that Hey 1 and Hey 2 are critical for preventing premature upregulation of Atoh1 in prosensory cells and loss of Heyl and Hey 2 results in premature HC differentiation along the developing cochlear duct.

\section{Loss of Heyl and Hey 2 results in abnormal distribution of $\mathrm{OHCs}$ along the cochlear duct}

To determine how loss of Hey1 and Hey2 might impact HC patterning, cochlear surface preparations and cochlear sections were prepared from neonatal Hey $1^{\Delta / \Delta} \mathrm{Hey} 2^{-/-}$(DKO) pups and $\mathrm{Hey} 2^{-/-}$and Hey2 $2^{-/+}$littermate controls and stained for $\mathrm{HC}$ markers. Immunostaining for MYO6 was used to visualize $\mathrm{HC}$ soma, and phalloidin staining was used to visualize the HCspecific actin-rich apical protrusions called stereocilia. It has previously been shown that, in Hes/Hey compound mutants, in which either Hey1 or Hey2 were codeleted with Hes1 and or Hes5, $\mathrm{HC}$ density and ectopic HCs are significantly increased compared with control tissue (Li et al., 2008; Tateya et al., 2011). Surprisingly, in Hey1-Hey2 double mutants (DKO), HC density as well as the total length of the sensory epithelium $(52.8 \pm 2.7 \mathrm{HCs} / 100$ $\mu \mathrm{m}, 6083.8 \pm 117.6 \mu \mathrm{m}, n=6)$ was not significantly different from Hey2 $2^{-/+}(48.6 \pm 1.2 \mathrm{HCs} / 100 \mu \mathrm{m}, 6206.8 \pm 89.8 \mu \mathrm{m}, n=$ 5) and Hey2 $2^{-/-}(51.8 \pm 0.6 \mathrm{HCs} / 100 \mu \mathrm{m}, 5863.7 \pm 178.2 \mu \mathrm{m}$, $n=5$ ) littermate controls, indicating that HCs were not overproduced in the absence of Heyl and Hey2. However, the precise cellular pattern of one row of IHCs and three rows of OHCs seen throughout the length of the auditory sensory epithelium in Hey2 single mutant (control) neonatal pups (Fig. $3 A, C, E$ ) was significantly altered in Hey1-Hey2 double mutant (DKO) pups (Fig. $3 B, D, F)$. In the absence of Heyl and Hey2, ectopic IHCs were most frequently observed in the cochlear mid-turn (Fig. 3D,I), whereas ectopic $\mathrm{OHCs}$ were most frequently observed in the cochlear base (Fig. $3 F, J$ ). Strikingly, in DKO cochleae, OHCs were frequently missing in the cochlear apex, and the sensory epithelium consisted only of two rows of OHCs instead of three (Fig.
$3 B, K)$. Moreover, mispatterned HCs in DKO cochleae frequently had deformed and misoriented stereocilia (Fig. $3 B, D, F$ ). In mice, patterning of auditory HCs as well as stereocilia orientation is not fully completed at birth, and both processes undergo refinement in the first postnatal days (Anniko, 1983). To determine whether the defects persist until later stages of postnatal refinement, we analyzed the HC patterning and stereocilia orientation in postnatal day 4 (P4) Hey $2^{-/-}$(Fig. $3 G$ ) and DKO cochlear tissue (Fig. $3 H$ ). Our examination revealed that both $\mathrm{HC}$ patterning defects and stereocilia defects were largely retained as exemplified by the OHC patterning defects and stereocilia defect seen in the cochlear apex of DKO pups at P4 (Fig. $3 H$ ). Next, we examined the SC phenotype in the Hey1-Hey2 double mutant cochlea (DKO). SOX2 immunostaining was used to mark all subtypes of SCs. Moreover, SC subtypes were further subdivided into inner SCs (inner border cells, inner phalangeal cells) and outer SCs (pillar cells and Deiters cells) based on nuclear morphology and relative position within the sensory epithelium. Outer SC (oSC) density and total length of the sensory epithelium were not significantly changed in neonatal DKO pups (68.4 \pm 1.2 oSCs/ $100 \mu \mathrm{m}, 5945 \pm 298 \mu \mathrm{m}, n=3)$ compared with Hey2 $2^{-/+}(65.7 \pm$ $1.0 \mathrm{oSCs} / 100 \mu \mathrm{m}, 6170.58 \pm 212 \mu \mathrm{m}, n=3)$ and Hey $2^{-/-}$ $(70.9 \pm 2.1 \mathrm{oSCs} / 100 \mu \mathrm{m}, 5706.5 \pm 145.5 \mu \mathrm{m}, n=3)$ littermate controls, suggesting that the oSCs were not overproduced in the absence of Heyl and Hey2. However, oSCs were similar to OHCs unevenly distributed along the Hey1-Hey2 double mutant cochlear duct, with ectopic oSCs in the cochlear base (Fig. 3O, $O^{\prime}, U$, white and yellow arrows) and missing oSCs in the cochlear apex (Fig. $3 M, M^{\prime}, Q$, white and yellow dashed line). Moreover, the occasional ectopic IHCs were accompanied by ectopic inner SCs (iSCs) as exemplified by supernumerary SOX2-positive iSCs in the cochlear mid-turn (Fig. 3S, white and yellow asterisk). In addition, we found evidence for late SC-to-HC conversion in DKO cochlea. In the late embryonic and early postnatal cochlea, Hey 1 and Hey 2 are coexpressed in outer pillar cells, suggesting a role in the differentiation or maintenance of outer pillar cells. To analyze the outer pillar cell phenotype, p75 immunostaining was used. In the early postnatal cochlea, the low-affinity neurotrophin receptor p75 (NGFR) is highly expressed on the apical surface of both outer and inner pillar cells (von Bartheld et al., 1991). Similar to Hey $2^{-1+}$ control tissue, in DKO cochlear surface preparations, p75-positive cells were clearly present in the in the pillar cell region, suggesting that pillar cells differentiate normally in the absence of Heyl and Hey2 (Fig. $3 V-W^{\prime}$ ). However, we observed occasional gaps in the p75-positive stripe, in which p75positive pillar cells were replaced by HCs, suggesting a late pillar cell-to-HC fate switch in the absence of Heyl and Hey2 (Fig. $3 W, W^{\prime}$, white asterisk). In summary, our analysis revealed that, in the absence of Heyl and Hey2, the normal cellular pattern of the auditory sensory epithelium is severely disrupted. Some of the patterning defects, such as the frequently observed ectopic IHCs, are shared with Hes single and Hes/Hey compound mutants and are likely due to defects in partition of the prosensory cell pool into HCs and SCs. However, the uneven distribution of OHCs and oSCs along the cochlear duct and the ectopic HCs within the pillar cell region is unique to Hey1-Hey2 double mutants and is consistent with a function of Heyl and Hey2 in prosensory cell maintenance and a later function in maintaining a pillar cell fate.

Loss of Hey 1 and Hey 2 does not alter the timing or pattern of prosensory cell cycle withdrawal

In the developing brain, HES and HEY transcription factors are critical for maintaining proliferation of neural stem cells and 
progenitor cells, and loss of Hes/Hey function results in premature cell cycle withdrawal (Sakamoto et al., 2003; Kageyama et al., 2008; Fujitani et al., 2010). Similarly, in the developing cochlea, loss of Hes1, which is expressed at low levels at the prosensory stage, results in premature cell cycle withdrawal (Murata et al., 2009). In the murine cochlea, cell cycle exit of prosensory cells occurs within a $48 \mathrm{~h}$ time window and follows an apical-to-basal gradient, with apical progenitors exiting first $\sim$ E12.5 and very basal progenitors exiting as late as E14.5 (Ruben, 1967; Lee et al., 2006). To determine whether loss of Heyl and Hey 2 might have caused premature cell cycle withdrawal, the rate of prosensory cell proliferation was analyzed at E13.5, the peak of cell cycle withdrawal in Hey2 $2^{-/-}$(control) and Hey $1^{\Delta / \Delta}$ Hey2 ${ }^{-/-}$(DKO) mice. Timedmated dams received a single injection of the thymidine analog EdU at E13.5 and EdU incorporation was analyzed 2 days later in cochlear sections using a chemical assay (Salic and Mitchison, 2008). SOX2 immunostaining was used to mark prosensory cells and their progenies (HC and SC precursors). We reasoned that, if HEY1 and HEY2 positively regulate prosensory cell proliferation, loss of Heyl and Hey2 should reduce the number of cycling SOX2-positive HC and SC precursors. However, an EdU pulse at E13.5 revealed no difference in overall proliferation, timing, or pattern of cell cycle withdrawal. SOX2-positive prosensory cells in control (Fig. $4 A, C, E$ ) and DKO (Fig. $4 B, D, F$ ) animals incorporated EdU at similar rates, showing a similar pattern of apical-tobasal cell cycle withdrawal with very low EdU incorporation in the cochlear apex and highest incorporation in the cochlear base (Fig. 4G). Next, we examined whether the onset of cell cycle withdrawal of HC and SC precursors occurs prematurely in the absence of Heyl and Hey2. Timed-mated dams received a single injection of EdU at E12.5, and EdU incorporation in IHCs and OHCs and oSCs was analyzed in cochlear surface preparations of DKO animals and Hey2 $2^{-/+}$and Hey $1^{\Delta / \Delta}$ $\mathrm{Hey} 2^{-/+}$control littermates, Stage E18.5. In littermate controls, EdU incorporation in MYO6-positive IHCs and OHCs declined from base to apex with the lowest frequency of EdU incorporation in the most apical region (Fig. $4 H-L, R, S$, light and dark gray bar). Similarly, in the absence of Heyl and Hey2, EdU incorporation in IHCs and OHCs gradually declined from base to apex, with the lowest frequency of EdU incorporation in the
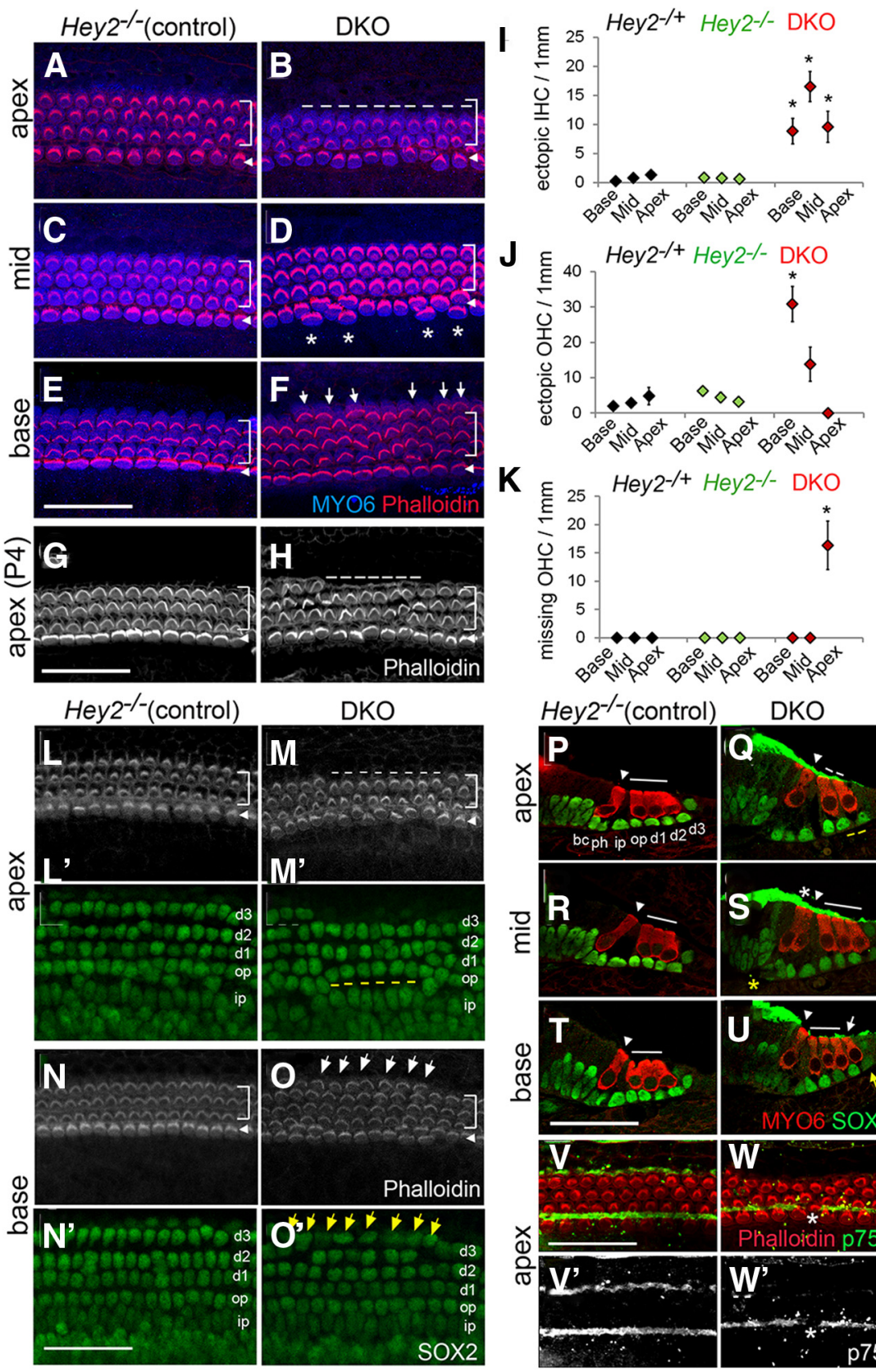

Figure 3. L Loss of Hey 1 and Hey2 results in complex HCand SC patterning defects. $\boldsymbol{A}-\boldsymbol{W}^{\prime}, \mathrm{HC}$ and SC phenotype was analyzed in the early postnatal control (Hey2 $2^{-/-}$and Hey2 ${ }^{-/+}$) and DKO cochlea in whole mounts (surface preparations) and sections. HCs were labeled using MY06 and phalloidin staining, and SCS were labeled using SOX2 staining. HC and SC subtypes were identified by morphology and their relative location within the sensory epithelium. Arrowheads indicate IHC domain; brackets indicate $\mathrm{OHC}$ domain. Dashed line indicates missing OHCs (white) and missing 0SCs (yellow). Asterisks label ectopic IHCs (white) and ectopiciSCs (yellow). Arrows indicate ectopic OHCs (white) and ectopic oSCs (yellow). bc, inner border cell; ph, inner phalangeal cell; ip, inner pillar cell; op, outer pillar cell; d1-3, Deiters cells. $\boldsymbol{A}-\boldsymbol{F}, \mathrm{HC}$ phenotype in Hey2 ${ }^{-/-}(\boldsymbol{A}, \boldsymbol{C}, \boldsymbol{E})$ and DKO $(\boldsymbol{B}, \boldsymbol{D}, \boldsymbol{F})$ cochlear surface preparations, Stage P0. Shown are high-power confocal images of MY06 and phalloidin-positive $H C$ layer at apical $(\boldsymbol{A}, \boldsymbol{B})$, $\operatorname{mid}(\boldsymbol{C}, \boldsymbol{D})$, and basal $(\boldsymbol{E}, \boldsymbol{F})$ positions. Scale bar, $50 \mu \mathrm{m}$. $\boldsymbol{G}, \boldsymbol{H}, \mathrm{HC}$ phenotype in Hey $2^{-/-}(\boldsymbol{G})$ and DKO $(\boldsymbol{H})$ cochlear surface preparations, Stage P4. Shown are high-power confocal images of the HC layer (phalloidin, white) at an apical location. Scale bar, $50 \mu \mathrm{m}$. $\boldsymbol{I}-\boldsymbol{K}$, Quantification of ectopic IHCs $(\boldsymbol{I})$, ectopic OHCs $(\boldsymbol{J})$, and missing 0HCs $(\boldsymbol{K})$ in DKO (red diamonds) and Hey $2^{-/-}$(green diamonds) and Hey $2^{-/+}$(black diamonds) cochlea Stage P0-P2. Cochlear surface preparations were divided into three segments (base, mid, apex), and ectopic and missing $\mathrm{HCs}$ were counted for each segment per $1 \mathrm{~mm}$. Data are mean \pm SEM ( $n=7$, three independent experiments). ${ }^{*} p \leq 0.05 . \boldsymbol{L}-\mathbf{0}^{\prime}, \mathrm{HC}$ and SC phenotype in DKO $\left(\boldsymbol{M}, \boldsymbol{M}^{\prime}, \mathbf{0}, \mathbf{0}^{\prime}\right)$ and Hey $2^{-/-}$(control) ( $\boldsymbol{L}_{\text {, }}$ $\left.\boldsymbol{L}^{\prime}, \mathbf{N}, \boldsymbol{N}^{\prime}\right)$ cochlear surface preparations, Stage P0. Shown are confocal images of the HC layer (phalloidin, white) and corresponding $\left({ }^{\prime}\right) S C$ layer (SOX2, green) of apical $\left(\boldsymbol{L}-\boldsymbol{M}^{\prime}\right)$ and basal segments $\left(\boldsymbol{N}-\mathbf{O}^{\prime}\right)$. Scale bar, $50 \mu \mathrm{m} . \boldsymbol{P}-\boldsymbol{U}, \mathbf{S C}$ phenotype in Hey $2^{-/-}($control) $(\boldsymbol{P}, \boldsymbol{R}, \boldsymbol{T})$ and DKO $(\boldsymbol{Q}, \boldsymbol{S}, \boldsymbol{U})$ cochlear sections, Stage P0. Shown are confocal images of apical $(\boldsymbol{P}, \boldsymbol{Q})$, mid $(\boldsymbol{R}, \boldsymbol{S})$, and basal $(\boldsymbol{T}, \boldsymbol{U})$ cochlear sections immunostained with HC marker MY06 (red) and SC marker SOX2 (green). Scale bar, $50 \mu \mathrm{m}$. V $-\boldsymbol{W}^{\prime}$, Pillar cell phenotype in Hey $2^{-/+}$ (control) $\left(\boldsymbol{V}, \boldsymbol{V}^{\prime}\right)$ and DKO $\left(\boldsymbol{W}, \boldsymbol{W}^{\prime}\right)$ cochlear surface preparations, Stage P0. Shown are merged and single (') channel confocal images of HC layer in cochlear apex. Phalloidin-positive HC bundles are shown in red, and p75 (NGFR)-positive pillar cell heads are shown in green and white ('). The pillar cell-specific p75 staining is disrupted by an ectopic HC (white asterisk) in the DKO cochlea (W, $\left.\boldsymbol{W}^{\prime}\right)$. Scale bar, $50 \mu \mathrm{m}$. 

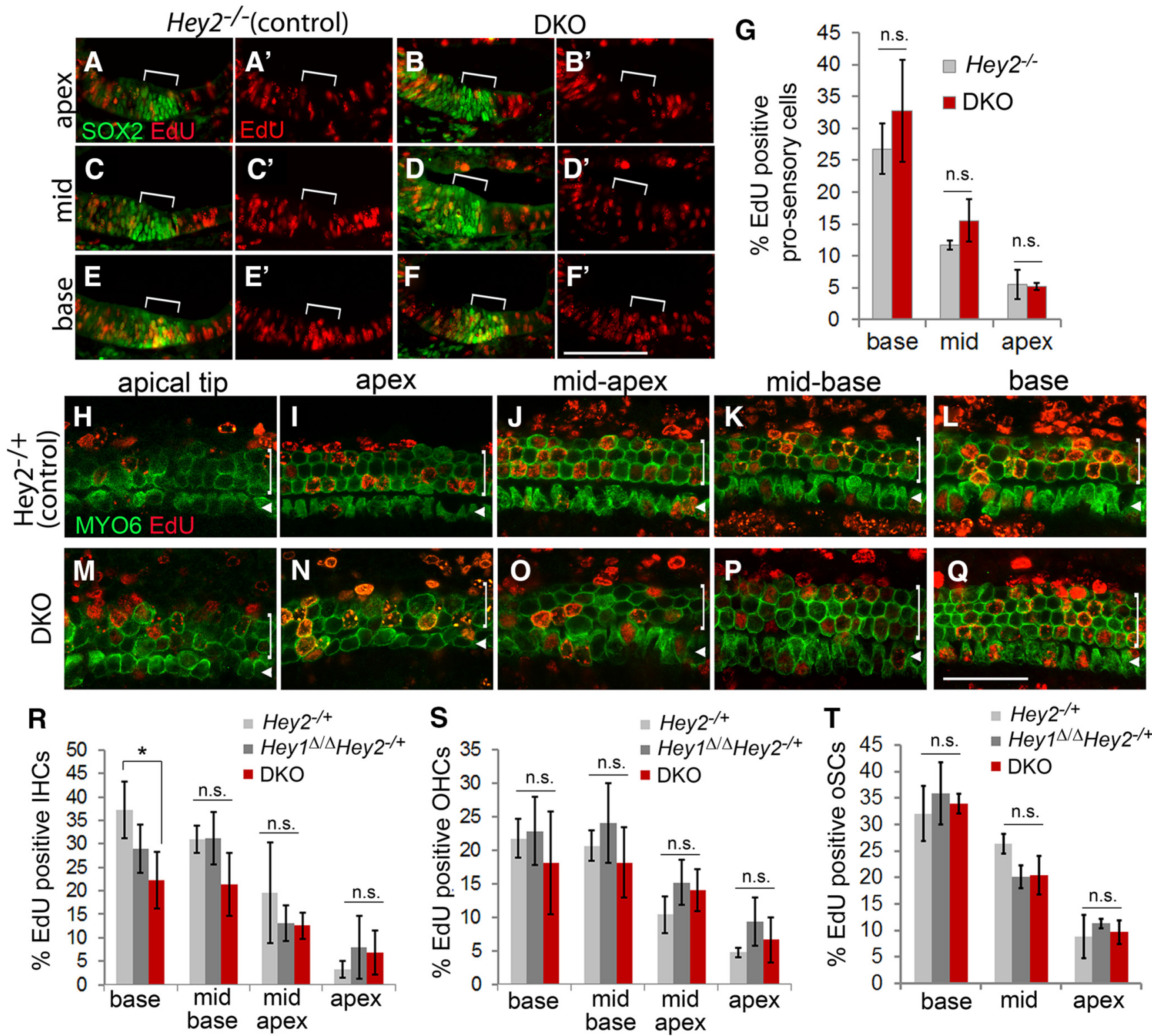

Figure 4. Loss of Hey 1 and Hey2 does not alter prosensory cell proliferation. A-G, Loss of Hey1 and Hey2 does not alter the apical-to-basal gradient of prosensory cell cycle exit. Incorporation of EdU in prosensory cells was analyzed in Hey2 ${ }^{-\prime-}\left(\right.$ control) $(\boldsymbol{A}, \boldsymbol{C}, \boldsymbol{E})$ and Hey $7^{\Delta / \Delta} \mathrm{Hey2} 2^{-\prime-}(\mathrm{DKO})(\boldsymbol{B}, \boldsymbol{D}, \boldsymbol{F})$ animals. EdU was injected at E13.5, and E15.5 cochlear sections were immunostained for prosensory marker SOX2 (green) and processed for EdU labeling (red). Shown are both merged and EdU only images (') for the cochlear apex $\left(\boldsymbol{A}-\boldsymbol{B}^{\prime}\right)$, mid $\left(\boldsymbol{C}-\boldsymbol{D}^{\prime}\right)$, and base $\left(\boldsymbol{E}-\boldsymbol{F}^{\prime}\right)$. White bracket indicates prosensory domain. Scale bar, $100 \mu \mathrm{m}$. G, Quantification of EdU incorporation in Hey2 ${ }^{-\prime-}$ control (gray bar) and DKO (red bar) prosensory cells in the cochlear apex, mid, and base. Data are mean \pm SEM $(n=3$, two independent experiments). n.S., Not significant. $\boldsymbol{H}-\boldsymbol{T}$, Loss of Hey1 and Hey2 does not alter proliferation rate of HC and SC precursors. EdU was injected at E12.5 and EdU incorporation in HCs and SCS was analyzed at E18.5 in control (Hey2 ${ }^{-/+}$and Hey $1^{\Delta / \Delta} H e y 2^{-/+}$) and DKO cochlear surface preparations. H-Q, EdU incorporation in E18.5 Hey2 ${ }^{-/+}$(control) $(\boldsymbol{H}-\mathbf{L})$ and DKO $(\boldsymbol{M}-\mathbf{Q})$ cochlear sensory epithelium. Shown are high-power confocal images of MY06-positive HClayer (green) at the cochlear apical tip $(\boldsymbol{H}, \boldsymbol{M})$, apex $(\boldsymbol{I}, \boldsymbol{N})$, mid-apex $(\boldsymbol{J}, \mathbf{O})$, mid-base $(\boldsymbol{K}, \boldsymbol{P})$, and base $(\boldsymbol{L}, \mathbf{Q})$. Arrows point to IHCs; brackets indicate $\mathrm{OHCs}$. EdU-positive nuclei are shown in red. Scale bar, $50 \mu \mathrm{m} . \boldsymbol{R}-\boldsymbol{T}$, Quantification of EdU incorporation in IHCs $(\boldsymbol{R}), \mathrm{OHCs}(\boldsymbol{S})$, and $0 \mathrm{SCS}$ $(\boldsymbol{T})$ in E18.5 Hey2 ${ }^{-/+}$(light gray), Hey ${ }^{\Delta / \Delta}$ Hey2 $2^{-/+}$(dark gray), and DKO (red). Data are mean \pm SEM $\left(n=3\right.$, two independent experiments). ${ }^{*} p \leq 0.05$. n.s., Not significant.

most apical region (Fig. $4 M-Q, R, S$, red bar). Moreover, loss of Heyl and Hey2 did not alter the spatiotemporal pattern of cell cycle withdrawal of SC precursors, as evidenced by the similar rate of EdU incorporation in control (Fig. 4T, light and dark gray bar) and DKO oSC precursors (Fig. 4T, red bar). The only differences we noted were that Hey1-Hey2 double mutant IHCs located in the cochlear base incorporated EdU at lower levels than $\mathrm{Hey} 2^{-/+}$control (Fig. 4R, red and light gray bar). The lower than normal EdU incorporation of basally located IHCs is likely to be a secondary effect due to forced cell cycle exit caused by their premature differentiation. In summary, our EdU incorporation data suggest that loss of Hey 1 and Hey2 does not significantly alter the overall proliferation rate of prosensory cells or the apical-tobasal pattern of prosensory cell cycle withdrawal.

Hedgehog signaling maintains Hey1 and Hey2 expression in prosensory cells

Hey 1 and Hey 2 are well-characterized transcriptional targets of Notch signaling. However, the regulation of Heyl and Hey2 expression in cochlear prosensory cells appears to be more complex, as loss of canonical Notch signaling has no effect on Heyl and Hey 2 mRNA expression in prosensory cells (Basch et al., 2011). A candidate pathway for positively regulating Heyl and Hey 2 transcription at the prosensory stage is Hedgehog signaling. 

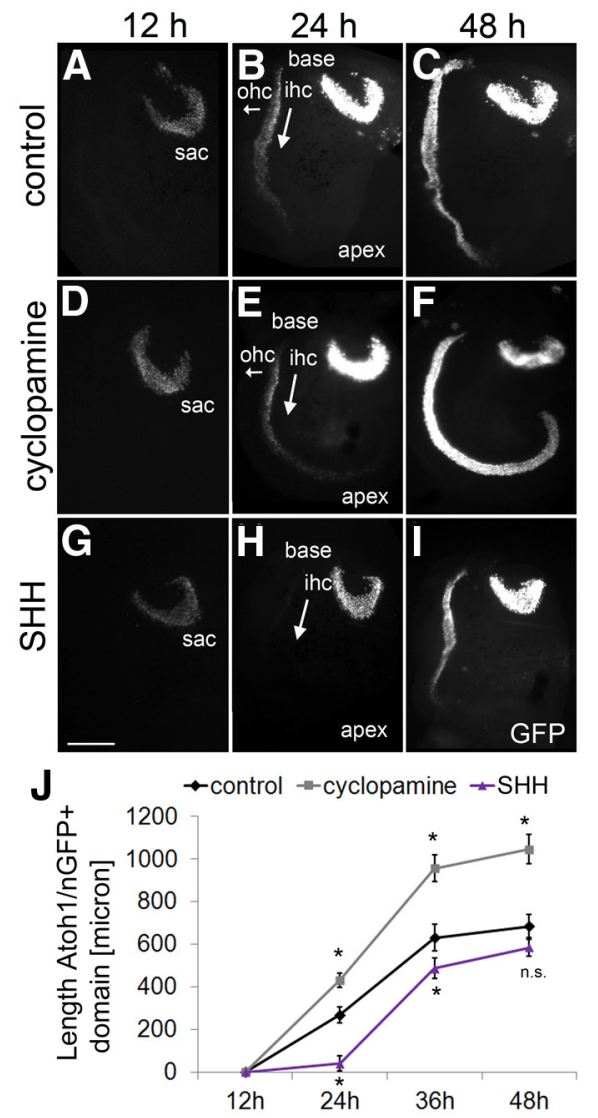
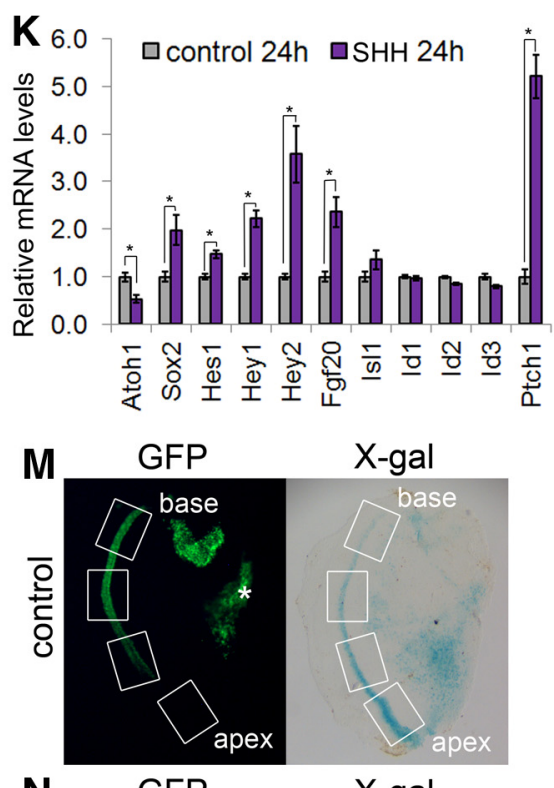

N

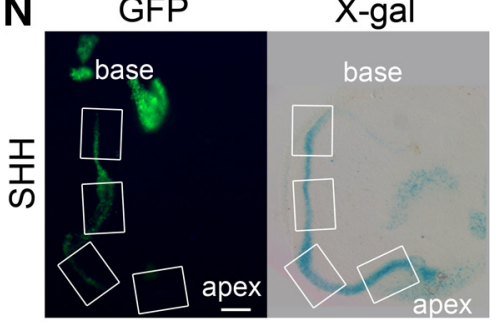

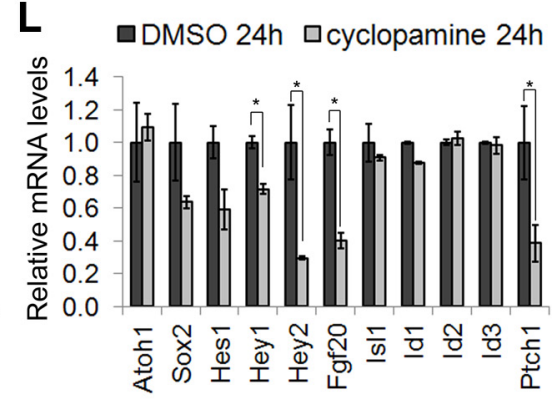

M'
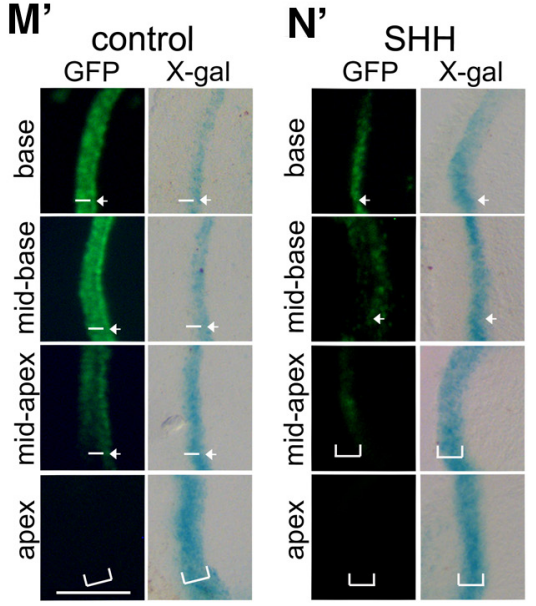

Figure 5. Hedgehog signaling positively regulates Hey1 and Hey2 expression in prosensory cells. A-I, Effects of Hedgehog signaling on HC differentiation. HC-specific Atoh1/nGFP reporter expression was monitored in control $(\boldsymbol{A}-\boldsymbol{C})$, cyclopamine $(\boldsymbol{D}-\boldsymbol{F})$, and SHH-treated $(\boldsymbol{G}-\boldsymbol{I})$ E13.0 cochlear explants over a $48 \mathrm{~h}$ time period. Shown are low-power fluorescent images of Atoh1/nGFP (GFP, white) at $12 \mathrm{~h}(\boldsymbol{A}, \boldsymbol{D}, \boldsymbol{G}), 24 \mathrm{~h}(\boldsymbol{B}, \boldsymbol{E}, \boldsymbol{H})$, and $48 \mathrm{~h}(\boldsymbol{C}, \boldsymbol{F}, \boldsymbol{I})$. Long arrows indicate basal-to-apical gradient; short arrows indicate medial-to-lateral gradient. Locations of IHCs (ihc) and 0HCs (ohc) and basal (base) to apical (apex) extent of cochlear duct are indicated. Atoh1/nGFP is also expressed in the vestibular sacculus (sac). Scale bar, $200 \mu \mathrm{m}$. J, Quantification of basal-to-apical extent of Atoh1/nGFP expression in control (black diamond), cyclopamine (gray square), and SHH (purple triangle) treated cochlea explants after $12,24,36$, and $48 \mathrm{~h}$. Data mean \pm SEM ( $n=5$ ). ${ }^{*} p \leq 0.05$. n.s., Not significant. $\boldsymbol{K}, \boldsymbol{L}$, Hedgehog signaling positively regulates Hey1 and Hey2 mRNA expression. $\boldsymbol{K}, \mathrm{qPCR}$-based analysis of cochlear epithelial-specific gene expression in SHH-treated (Shh, purple bar) and untreated (control, gray bar) E13.5 cochlear explants after $24 \mathrm{~h}$ in vitro. Data are mean $\pm S E M\left(n=4\right.$, two independent experiments). ${ }^{*} \leq \leq 0.05$. $L$, qPCR based analysis of cochlear epithelial-specific gene expression in cyclopamine (light gray bar) and vehicle control (DMSO, dark gray bar) treated E13.5 cochlear explants after $24 \mathrm{~h}$ in vitro. Data are mean \pm SEM ( $n=4$, two independent experiments). ${ }^{*} p \leq 0.05 . \boldsymbol{M}-\boldsymbol{N}^{\prime}$, Hedgehog signaling maintains Hey2 expression in prosensory cells. E13.5 Atoh1/nGFP transgenic Hey2 ${ }^{\text {LacZ/+ }}$ cochlear explants were cultured with ( $\boldsymbol{N}$, $\left.\boldsymbol{N}^{\prime}\right)$ and without SHH $\left(\boldsymbol{M}, \boldsymbol{M}^{\prime}\right)$ for $48 \mathrm{~h}$. Shown are low-power $(\boldsymbol{M}, \boldsymbol{N})$ and high-power $\left(\boldsymbol{M}^{\prime}, \boldsymbol{N}^{\prime}\right)$ images of HC-specific Atoh1/nGFP reporter expression (GFP, green) and Hey2-LacZ reporter expression (X-gal, blue). $\boldsymbol{M}, \boldsymbol{N}$, White boxes represent the fields along the cochlear duct shown in $\boldsymbol{M}^{\prime}$ and $\boldsymbol{N}^{\prime} . \boldsymbol{M}^{*}{ }^{*}$ Auto-fluorescent debris. $\boldsymbol{M}^{\prime}, \boldsymbol{N}^{\prime}, \mathrm{White}$ brackets indicate undifferentiated prosensory domain; white arrowheads indicate location of GFP-positive IHCs; white bars indicate location of GFP-positive OHCs. Scale bar, $100 \mu \mathrm{m}$.

Overactivation of Hedgehog signaling in the undifferentiated cochlea blocks Atoh1 induction and subsequently HC generation (Driver et al., 2008; Tateya et al., 2013), and there is mounting evidence that a Hedgehog activity gradient controls the gradient of $\mathrm{HC}$ differentiation. Hedgehog signaling in prosensory cells is thought to be activated by the Hedgehog ligand $\mathrm{SHH}$, which is transiently produced by spiral ganglion neurons during cochlear outgrowth (Driver et al., 2008; Liu et al., 2010). Spiral ganglionspecific deletions of Shh result in severe to moderate cochlear outgrowth defects dependent on the time of ablation. In addition, deletion of Shh causes prosensory cells to drop out of the cell cycle prematurely and to differentiate precociously (Bok et al., 2013). Similarly, the cochlear-specific genetic ablation of Smoothened (Smo), which encodes for a critical transduction component of Hedgehog signaling, results in precocious HC differentiation (Tateya et al., 2013). To examine the relationship among Hedgehog signaling, Hey 1 and Hey2 expression, and HC differentiation, we made use of a well-characterized cochlear explant system in which the developing cochlear epithelial duct and its innervating spiral ganglion are cultured in the presence of mesenchyme (Montcouquiol and Kelley, 2003; Doetzlhofer et al., 2009). Native nuclear GFP expression of the HC-specific Atoh $1 / n$ GFP line was used to monitor the dynamics of HC differentiation. Exogenous $\mathrm{SHH}$ protein was added to stimulate Hedgehog signaling, and cyclopamine, a steroidal alkaloid known to inhibit SMO (Chen et al., 2002a), was added to inhibit Hedgehog signaling in Stage E13.5 cochlear tissue. At plating and after $12 \mathrm{~h}$ in vitro, untreated (control), SHH-treated, and cyclopamine-treated explants showed no HC-specific Atoh1/ $n G F P$ expression in the developing cochlear duct (Fig. $5 A, D, G$ ). However, after $24 \mathrm{~h}$ in vitro, striking differences in the basal-toapical progression of $\mathrm{HC}$ differentiation emerged. In cochlear explants treated with cyclopamine, IHC differentiation was further progressed (Fig. $5 E, J$ ) than in untreated control cultures (Fig. $5 B, J$ ). However, cochlear explants treated with exogenous SHH contained no or only few GFP-positive HCs after $24 \mathrm{~h}$ in vitro (Fig. $5 \mathrm{H}, \mathrm{J}$ ). After $48 \mathrm{~h}$ in vitro, differences in the extent of $\mathrm{OHC}$ differentiation (medial-to-lateral gradient) emerged, with $\mathrm{OHC}$ differentiation being more advanced in cyclopaminetreated explants (Fig. 5C,F) and less advanced in $\mathrm{SHH}$-treated 
explants compared with control explants (Fig. 5C,I). To determine whether Heyl and Hey2 might be targets of Hedgehog signaling, we analyzed the transcript levels of Heyl and Hey2 in enzyme-purified cochlear epithelia after $24 \mathrm{~h}$ of SHH-mediated Hedgehog overactivation (Fig. $5 \mathrm{~K}$ ) or cyclopamine-mediated Hedgehog inhibition (Fig. 5L). To confirm successful overactivation or inhibition of Hedgehog signaling in our experimental paradigm, we included in our qPCR analysis the known Hedgehog target gene Ptch1 (Patched homolog 1) (Vokes et al., 2007). Our qPCR-based analysis revealed that Hey1, Hey2, and Ptch1 transcripts were significantly increased in SHH-treated cochlear explants compared with untreated control explants (Fig. $5 \mathrm{~K}$ ). Conversely, in the presence of Hedgehog inhibitor cyclopamine, Hey1, Hey2, and Ptch1 transcripts were significantly reduced compared with explants treated with vehicle control DMSO (Fig. $5 L$ ). The modest but significant reduction of Heyl transcript levels in cyclopamine-treated cultures suggests that Hedgehogindependent mechanisms might compensate for the loss of Hedgehog signaling. A significant increase in transcript levels in response to Hedgehog overactivation was also observed for Sox2, Hes1, and Fibroblast growth factor 20 (Fgf20) (Fig. 5K). Similar to Heyl and Hey2, Hes1, Sox2, and Fgf20 are positively regulated by Notch signaling in the developing cochlea (Takebayashi et al., 2007; Dabdoub et al., 2008; Hayashi et al., 2008a, b), suggesting cooperation between Notch and Hedgehog signaling in maintaining their expression in prosensory cells. We also examined the mRNA expression of the prosensory-specific HLH factors and known ATOH1 antagonists ID1, ID2, ID3, and the prosensory-specific transcription factor ISLET1 (ISL1) (RaddeGallwitz et al., 2004; Jones et al., 2006). However, none of these transcripts showed Hedgehog dependency, suggesting that modulation of Hedgehog signaling does not globally alter progenitor-specific gene expression (Fig. $5 K, L$ ). To determine how Hedgehog signaling affects the spatial and temporal pattern of Hey2 expression, we made use of our Hey2 knock-out line, in which exon 2 of the Hey 2 gene was knocked out by LacZ insertion $\left(\right.$ Hey $\left.^{2 \text { LacZ/+ }}\right)($ Gessler et al., 2002). E13.0 Atoh1n/GFP transgenic $\mathrm{Hey} 2^{\mathrm{LacZ} /+}$ cochlear explants were cultured in the absence (control) or presence of exogenous $\mathrm{SHH}$, and after $48 \mathrm{~h}$ in vitro Hey2LacZ expression was analyzed using the X-gal assay (Fig. $5 M-N^{\prime}$; $\mathrm{X}$-gal). GFP expression marked HCs and IHCs (arrowhead) and OHCs (bar) were identified by their location within the sensory epithelium (Fig. $5 M-N^{\prime}$; GFP). In control cochlear explants, broad Hey 2 expression in the undifferentiated cochlear apex narrowed to the OHC domain in the cochlear mid-apex. In the differentiated cochlear mid-base and base, which already contained both IHCs and OHCs, Hey2 expression was limited to the pillar cell region (Fig. $5 \mathrm{M}, \mathrm{M}^{\prime}$ ). However, in cochlear explants treated with exogenous $\mathrm{SHH}, \mathrm{Hey} 2 \mathrm{remained}$ broadly expressed throughout most of the length of the cochlear duct, strongly correlating with the delayed upregulation of GFP in HCs (Fig. $5 N, N^{\prime}$ ). Together, our analysis identifies Heyl and Hey 2 as targets and likely effector genes of Hedgehog signaling in the developing cochlea.

\section{FGF signaling functions downstream of Hedgehog signaling in Heyl and Hey 2 regulation}

A recent study has shown that forced expression of a constitutively active Smo allele (Smo-M2) results in prolonged Fgf2O expression in prosensory cells and a permanent block of $\mathrm{OHC}$ differentiation. Interestingly, interference with FGF20-activated FGFR signaling reverses the inhibitory effect of Hedgehog overactivation in E17.5 R26-Smo-M2 transgenic cochlear explants and restores OHC differentiation (Tateya et al., 2013). We recently have shown that FGFR signaling cooperates with Notch signaling in the transcriptional regulation of $\mathrm{Hey}_{2}$ in pillar cells (Doetzlhofer et al., 2009), and an intriguing scenario is that FGFR signaling might similarly contribute to the regulation of Hey2 in prosensory cells. To determine whether FGFR signaling is required for the positive effects of Hedgehog signaling on Heyl and Hey 2 expression, E13.5 Atoh1/nGFP transgenic cochlear explants were cultured in the presence of FGFR kinase inhibitor SU5402 (Mohammadi et al., 1997), SHH and SU5402, SHH and DMSO, or DMSO for $24 \mathrm{~h}$ (Fig. $6 \mathrm{~A}-\mathrm{H}$ ). Compared with vehicle control (DMSO), treatment with SU5402 did not alter the onset of HC differentiation (Fig. $6 A, B$ ), nor did it alter the rate at which HC differentiation progressed toward the cochlear apex (Fig. 6E,F,I). However, cotreatment with SHH and FGFR inhibitor ( $\mathrm{SHH}+$ SU5402) reversed the inhibitory effect of Hedgehog overactivation $(\mathrm{SHH}+\mathrm{DMSO})$ on HC differentiation (Fig. $6 G-I)$. Next, we analyzed whether FGF signaling is required for Hedgehog mediated activation of Hey2 and or Heyl transcription. Treatment of E13.5 cochlear explants with exogenous SHH (SHH + DMSO) increased Fgf20, Hey2, and Ptch1 expression by $>3$-fold and increased Heyl expression $\sim 2$-fold (Fig. $6 J$ ). However, cotreatment of cochlear explant cultures with SHH and FGFR inhibitor (SHH + SU5402) largely reversed the positive effects of SHH treatment (SHH + DMSO) on Hey2 and Heyl expression (Fig. 6J). Importantly, cotreatment with SHH and SU5402 did not alter expression of the known Hedgehog target gene Ptch1, nor did it alter the expression of $F g f 20$, suggesting that cotreatment with SU5402 did not globally attenuate SHH-activated Hedgehog signaling. However, in contrast to cyclopamine treatment, which reduced both Heyl and Hey2 levels (Fig. 5L), SU5402 treatment did not reduce Heyl and Hey 2 mRNA levels compared with the control (Fig. $6 J$ ). This could be in part due to incomplete inhibition of FGFR signaling in our experimental paradigm. Alternatively, FGFR-independent Hedgehog signaling mechanisms might maintain Heyl and Hey2 expression in the absence of FGFR signaling. Further studies are needed to determine the mechanisms of FGFR-dependent regulation of Heyl and Hey 2 expression in prosensory cells.

\section{Discussion \\ Hey 1 and Hey 2 prevent premature Atoh 1 upregulation in prosensory cells}

Heyl and Hey2, which are highly expressed in prosensory cells in the developing cochlea, have been recently implicated in prosensory cell specification downstream of Notch signaling (Hayashi et al., 2008b). However, our loss-of-function data suggest that Heyl and $\mathrm{Hey} 2$ are dispensable for prosensory domain specification but are critical components of the molecular machinery that negatively controls the graded upregulation of Atohl in HC precursors during cochlear differentiation. In the murine cochlea, Atoh1 promoter activity can be detected in prosensory cells as early as E12.5 (Woods et al., 2004; Yang et al., 2010; Driver et al., 2013). In contrast, Atoh1 transcript and protein levels are exceedingly low at this stage. Starting at E13.5-E14.0, Atoh1 transcript and protein are rapidly induced in nascent HCs following the basal-to-apical and medial-to-lateral gradient of HC differentiation, suggesting the existence of a regulatory mechanism that negatively regulates the graded upregulation of Atohl in HC precursors (Chen et al., 2002b; Groves et al., 2013). Our expression and functional data identify Heyl and Hey2 as an integral part of this negative regulatory mechanism. We show that Heyl and Hey 2 downregulation occurs independently of Atohl, indicating 


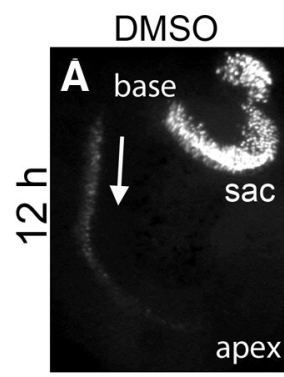

SU5402

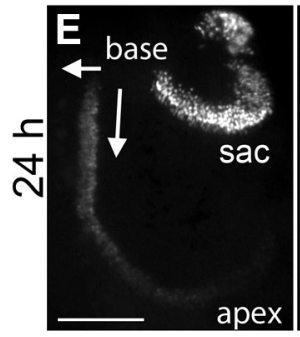

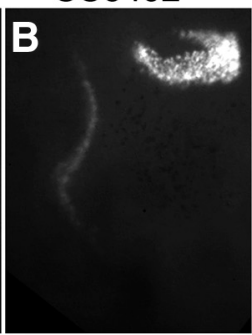

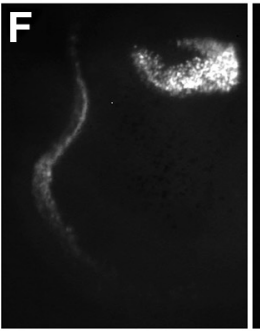

$\mathrm{SHH}+\mathrm{DMSO}$
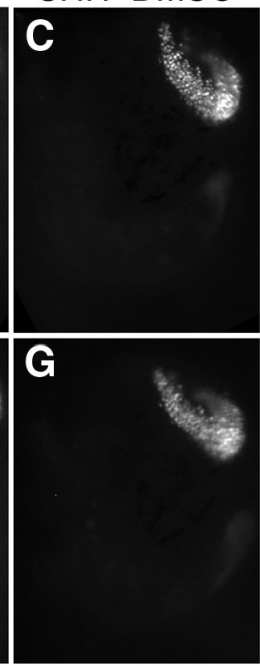

$\mathrm{SHH}+\mathrm{SU} 5402$

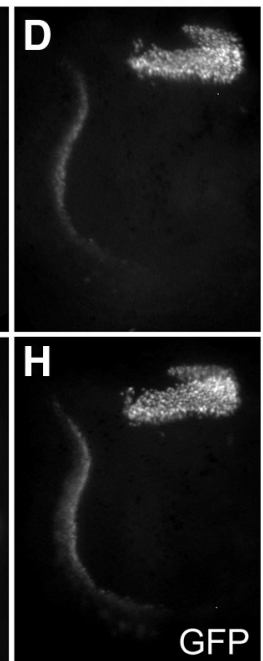

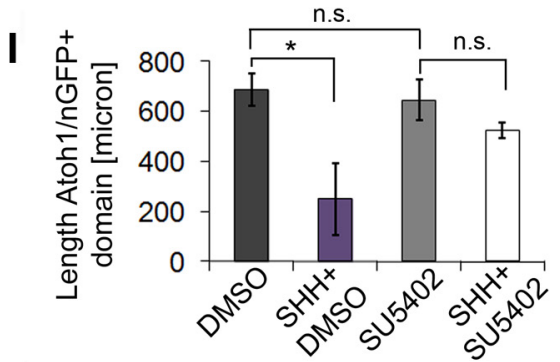

J

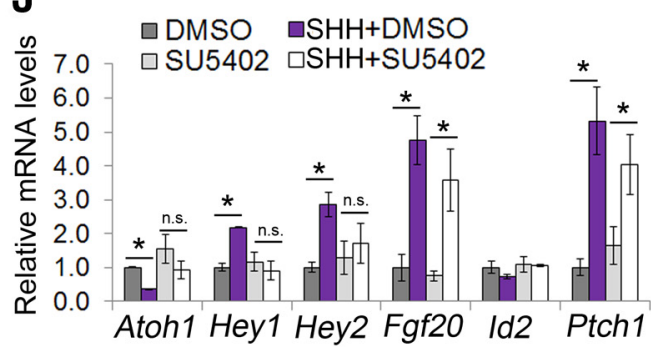

Figure 6. FGFR signaling acts downstream of Hedgehog signaling in Hey1 and Hey2 regulation. $\boldsymbol{A}-\boldsymbol{I}$, FGFR signaling is required for SHH-mediated inhibition of HC differentiation. HC-specific Atoh1/nGFP reporter expression was monitored in E13.5 cochlear explants treated with vehicle control DMSO $(\boldsymbol{A}, \boldsymbol{E})$, FGFR inhibitor SU5402 $(\boldsymbol{B}, \boldsymbol{F}), \mathrm{SHH}+\mathrm{DMSO}(\boldsymbol{C}, \boldsymbol{G})$, and SU5402 + SHH $(\boldsymbol{D}, \boldsymbol{H})$ over a $24 \mathrm{~h}$ time period. Shown are low-power fluorescent images of HC-specific Atoh $1 / \mathrm{hGFP}$ expression (GFP, white) at $12 \mathrm{~h}(\boldsymbol{A}-\boldsymbol{D})$ and $24 \mathrm{~h}(\boldsymbol{E}-\boldsymbol{H})$. Long arrow indicates basal-to-apical gradient; short arrow indicates medial-to-lateral gradient. I, Quantification of basal-to-apical extent of HC-specific Atoh1/nGFP expression in DMSO (dark gray bar), SHH + DMSO (purple bar), SU5402 (light gray bar), and SHH + SU5402 (white bar). Error bars indicate mean \pm SEM $(n=5)$. ${ }^{*} p \leq 0.05$. n.S., Not significant. J, FGFR signaling is required for SHH-mediated activation of Hey1 and Hey2 transcription. Shown is qPCR-based analysis of Hey1 and Hey2 mRNA levels in control (dark gray bar), SHH (purple bar), SU5402 (light gray bar), and SHH + SU5402 (white bar) treated cochlear epithelia after a $24 \mathrm{~h}$ treatment. Scale bar, $200 \mu \mathrm{m}$. Errors bars indicate mean \pm SEM ( $n=3$, two independent experiments). ${ }^{*} p \leq 0.05$. n.S., Not significant.

that Heyl and Hey2 act upstream of Atoh1 in the differentiating cochlea. Moreover, we demonstrate that genetic inactivation of Hey 1 and Hey 2 results in premature upregulation of Atoh1 transcript and Atoh1 enhancer activity (Atoh1/nGFP) in IHC and $\mathrm{OHC}$ precursors. Similarly, a decrease in expression of Heyl and Hey 2 due to loss of Hedgehog signaling results in premature induction of HC-specific Atoh $1 / n$ GFP in the developing cochlea, whereas an increase in Heyl and Hey2 expression due to overactivation of Hedgehog signaling delays HC-specific Atoh1/nGFP expression. How do HEY1 and HEY2 inhibit Atoh1 expression? It is likely that HEY1 and HEY2 interfere with the ability of ATOH1 to auto-regulate its own expression. Such interference could take place on a posttranscriptional level, as both HEY1 and HEY2 are known to bind to ATOH1, which would render ATOH1 inactive (Sakamoto et al., 2003; Doetzlhofer et al., 2009). In addition, HEY1 and HEY2 could bind to Hey binding motifs present in the Atoh1 auto-regulatory enhancer element and interfere with Atoh1 auto-regulation on a transcriptional level (Helms et al., 2000; Lumpkin et al., 2003; Heisig et al., 2012).

\section{Hey 1 and Hey 2 are not required for maintaining prosensory cell proliferation}

In the developing brain, HES/HEY factors are critical for maintaining neuronal stem cells/progenitor cells in the cell cycle, and their continued expression prevents premature differentiation (Sakamoto et al., 2003; Kageyama et al., 2008). In contrast to the dual role of HEY1 and HEY2 in neuronal stem cell/progenitor cell proliferation and differentiation, our data indicate that loss of Heyl and Hey2 only affects HC and SC differentiation without altering prosensory cell proliferation or cell cycle withdrawal. Interestingly, a recent study by Murata et al. (2009) revealed that HES1, which is broadly expressed in the developing cochlear epithelium before differentiation, is critical for prosensory cell proliferation, and loss of Hes 1 results in premature cell cycle withdrawal of prosensory cells. However, loss of Hes 1 does not alter the timing of HC and SC differentiation. These findings suggest that, in the developing cochlea, HES1 and HEY1/HEY2 play divergent roles at the prosensory stage, with HES1 being required for keeping prosensory cells proliferating and HEY1/HEY2 being required for maintaining prosensory cells undifferentiated.

Hey 1 and Hey 2 are required for proper HC and SC patterning Previous work demonstrated that HEY1 and HEY2, in cooperation with HES1 and HES5, play a central role in patterning the auditory sensory epithelium (Li et al., 2008; Tateya et al., 2011). In contrast to Hes/Hey compound mutants in which both $\mathrm{HC}$ density and the total number of HCs are significantly increased (Li et al., 2008; Tateya et al., 2011), the total number of HCs is not significantly changed in the absence of Heyl and Hey2. Instead, $\mathrm{OHCs}$ and oSCs are unevenly distributed along the cochlear duct, with ectopic OHCs and ectopic oSCs being frequently found in the cochlear base and OHCs and oSCs are frequently missing in the cochlear apex. Our analysis did not reveal any defects in the prosensory cell formation, proliferation, or cell cycle withdrawal in the absence of Heyl and Hey2, suggesting that this unique defect in OHC patterning arises during cellular differentiation. In parallel with cellular differentiation, the auditory sensory epithelium undergoes dramatic changes in both width and length. Convergence and extension (CE) under the control of the planar cell polarity (PCP) pathway (Wang et al., 2005) is thought to drive these changes. In CE/PCP mutants, HCs are misaligned, HC bundles are misoriented, and the number of $\mathrm{OHC}$ rows varies (Etheridge et al., 2008; Narimatsu et al., 2009). It is plausible that the premature onset of $\mathrm{HC}$ differentiation in the absence of Hey 1 and Hey 2 alters or disrupts CE of the auditory sensory epithelium. Alternatively, loss of Heyl and Hey2 might deregulate genes directly or indirectly involved in CE/PCP. Future studies will have to determine whether and how the CE/PCP pathway is affected in Hey1-Hey2 double-mutant cochlea. The continued expression of Hey 1 and Hey 2 in a subset of SC precursors and, later, in outer 
pillar cells suggests that defects in SC maintenance contribute to the complex patterning defect seen in the absence of these factors. Consistent with a role for Heyl and Hey2 in SC maintenance, p75-positive pillar cells are occasionally replaced by ectopic HCs in Hey1-Hey2 double mutant cochlea, which suggests a late pillar cell-to-HC fate switch.

\section{Hedgehog signaling positively regulates Heyl and Hey2 expression in prosensory cells}

Heyl and Hey2 are well-characterized Notch target genes and function as Notch effectors in many tissues. Canonical Notch signaling requires the function of transcription factor RBPJ (Kopan and Ilagan, 2009). Similar to Hes1 and Hes5, both Hey1 and Hey 2 contain multiple RBPJ binding sites (Maier and Gessler, $2000)$; and, based on in vitro $\gamma$-secretase inhibition experiments, it has been suggested that prosensory-specific expression of Heyl and Hey 2 is under the control of Notch signaling (Hayashi et al., $2008 b$ ). However, conditional ablations of $R b p j$ have resulted in either no change (Basch et al., 2011) or only modest reduction in prosensory Heyl and Hey2 expression (Yamamoto et al., 2011), suggesting that, in addition to Notch signaling, Notch-independent mechanisms control Heyl and Hey2 expression in prosensory cells.

Here we identify Hedgehog signaling as a critical positive regulator of Hey 1 and Hey 2 expression in prosensory cells. Furthermore, our regulatory data identify Hes1 and Sox2 as novel Hedgehog targets in the developing cochlea and confirm a recent report that has indicated $\mathrm{Fg} 20$ as a novel Hedgehog target gene (Tateya et al., 2013). Similar to Hey1 and Hey2, Hes1, Fgf20, and Sox2 have been shown to be positively regulated by Notch signaling in the developing cochlea (Takebayashi et al., 2007; Dabdoub et al., 2008; Hayashi et al., 2008a, b). Interestingly, in various neuronal stem/progenitor cell populations, a similar Hedgehogdependent regulation of canonical Notch target genes has been reported (Takanaga et al., 2009; Wall et al., 2009; Wu et al., 2012), suggesting that cooperation between Notch and Hedgehog signaling might constitute a broadly applied mechanism for maintaining neuronal stem cells and progenitor cells.

Previous loss-of-function studies have revealed that FGF20activated FGFR signaling is required for specification/survival of OHC precursors (Hayashi et al., 2008a; Huh et al., 2012). In addition, a recent study has demonstrated that FGF20-activated FGFR signaling mediates the OHC blocking function of excessive Hedgehog signaling, suggesting that FGF20-activated FGFR signaling, initially required for $\mathrm{OHC}$ specification, needs to be turned off or turned down for OHC differentiation to proceed (Tateya et al., 2013). Here we confirm the importance of FGFR activity in mediating the HC-repressive function of Hedgehog signaling and identify Heyl and Hey2 as targets and potential effectors of this FGFR-dependent Hedgehog activity. It should be noted that the difference in phenotypes in Hedgehog pathway mutants, Fgf20 mutants, and Hey1-Hey2 double mutants suggests that $\mathrm{SHH}$ may be regulating other pathways in the cochlea and that FGF20 is not solely functioning through regulating Hey1 and Hey2 (Huh et al., 2012; Bok et al., 2013; Tateya et al., 2013). Interestingly, FGFR inhibition by itself did not alter Heyl and Hey 2 expression or HC differentiation, whereas inhibition of Hedgehog signaling resulted in a significant reduction of Heyl and Hey 2 expression and a significant acceleration of HC differentiation. How can this be explained? The most likely explanation is that FGFR-independent Hedgehog signaling mechanisms may have compensated for the loss of FGFR signaling. In addition, it is likely that FGFR activity was not completely shut down in our experimental paradigm but was rather reduced, which in case of Hedgehog overactivation reset FGFR signaling back to baseline levels, allowing Heyl and Hey2 downregulation and $\mathrm{OHC}$ differentiation to proceed. Additional investigations will be necessary to determine the mechanisms of FGFR-dependent regulation of Heyl and Hey 2 in prosensory cells.

\section{References}

Anniko M (1983) Postnatal maturation of cochlear sensory hairs in the mouse. Anat Embryol 166:355-368. CrossRef Medline

Basch ML, Ohyama T, Segil N, Groves AK (2011) Canonical Notch signaling is not necessary for prosensory induction in the mouse cochlea: insights from a conditional mutant of RBPjkappa. J Neurosci 31:8046-8058. CrossRef Medline

Bermingham NA, Hassan BA, Price SD, Vollrath MA, Ben-Arie N, Eatock RA, Bellen HJ, Lysakowski A, Zoghbi HY (1999) Math1: an essential gene for the generation of inner ear hair cells. Science 284:1837-1841. CrossRef Medline

Bok J, Zenczak C, Hwang CH, Wu DK (2013) Auditory ganglion source of Sonic hedgehog regulates timing of cell cycle exit and differentiation of mammalian cochlear hair cells. Proc Natl Acad Sci U S A 110:1386913874. CrossRef Medline

Cai T, Seymour ML, Zhang H, Pereira FA, Groves AK (2013) Conditional deletion of atoh1 reveals distinct critical periods for survival and function of hair cells in the organ of Corti. J Neurosci 33:10110-10122. CrossRef Medline

Chen JK, Taipale J, Cooper MK, Beachy PA (2002a) Inhibition of Hedgehog signaling by direct binding of cyclopamine to Smoothened. Genes Dev 16:2743-2748. CrossRef Medline

Chen P, Segil N (1999) p27(Kip1) links cell proliferation to morphogenesis in the developing organ of Corti. Development 126:1581-1590. Medline

Chen P, Johnson JE, Zoghbi HY, Segil N (2002b) The role of Math1 in inner ear development: uncoupling the establishment of the sensory primordium from hair cell fate determination. Development 129:2495-2505. Medline

Dabdoub A, Puligilla C, Jones JM, Fritzsch B, Cheah KS, Pevny LH, Kelley MW (2008) Sox2 signaling in prosensory domain specification and subsequent hair cell differentiation in the developing cochlea. Proc Natl Acad Sci U S A 105:18396-18401. CrossRef Medline

Doetzlhofer A, Basch ML, Ohyama T, Gessler M, Groves AK, Segil N (2009) Hey2 regulation by FGF provides a Notch-independent mechanism for maintaining pillar cell fate in the organ of Corti. Dev Cell 16:58-69. CrossRef Medline

Driver EC, Pryor SP, Hill P, Turner J, Rüther U, Biesecker LG, Griffith AJ, Kelley MW (2008) Hedgehog signaling regulates sensory cell formation and auditory function in mice and humans. J Neurosci 28:7350-7358. CrossRef Medline

Driver EC, Sillers L, Coate TM, Rose MF, Kelley MW (2013) The Atoh1lineage gives rise to hair cells and supporting cells within the mammalian cochlea. Dev Biol 376:86-98. CrossRef Medline

Etheridge SL, Ray S, Li S, Hamblet NS, Lijam N, Tsang M, Greer J, Kardos N, Wang J, Sussman DJ, Chen P, Wynshaw-Boris A (2008) Murine dishevelled 3 functions in redundant pathways with dishevelled 1 and 2 in normal cardiac outflow tract, cochlea, and neural tube development. PLoS Genet 4:e1000259. CrossRef Medline

Fischer A, Gessler M (2007) Delta-Notch- and then? Protein interactions and proposed modes of repression by Hes and Hey bHLH factors. Nucleic Acids Res 35:4583-4596. CrossRef Medline

Fischer A, Schumacher N, Maier M, Sendtner M, Gessler M (2004) The Notch target genes Heyl and Hey2 are required for embryonic vascular development. Genes Dev 18:901-911. CrossRef Medline

Fischer A, Klattig J, Kneitz B, Diez H, Maier M, Holtmann B, Englert C, Gessler M (2005) Hey basic helix-loop-helix transcription factors are repressors of GATA4 and GATA6 and restrict expression of the GATA target gene ANF in fetal hearts. Mol Cell Biol 25:8960-8970. CrossRef Medline

Fujitani M, Cancino GI, Dugani CB, Weaver IC, Gauthier-Fisher A, Paquin A, Mak TW, Wojtowicz MJ, Miller FD, Kaplan DR (2010) TAp73 acts via the bHLH Hey2 to promote long-term maintenance of neural precursors. Curr Biol 20:2058-2065. CrossRef Medline

Gessler M, Knobeloch KP, Helisch A, Amann K, Schumacher N, Rohde E, Fischer A, Leimeister C (2002) Mouse gridlock: no aortic coarctation or 
deficiency, but fatal cardiac defects in Hey $2^{-/-}$mice. Curr Biol 12:16011604. CrossRef Medline

Groves AK, Zhang KD, Fekete DM (2013) The genetics of hair cell development and regeneration. Annu Rev Neurosci 36:361-381. CrossRef Medline

Hayashi T, Ray CA, Bermingham-McDonogh O (2008a) Fgf20 is required for sensory epithelial specification in the developing cochlea. J Neurosci 28:5991-5999. CrossRef Medline

Hayashi T, Kokubo H, Hartman BH, Ray CA, Reh TA, BerminghamMcDonogh O (2008b) Hesr1 and Hesr2 may act as early effectors of Notch signaling in the developing cochlea. Dev Biol 316:87-99. CrossRef Medline

Heisig J, Weber D, Englberger E, Winkler A, Kneitz S, Sung WK, Wolf E, Eilers M, Wei CL, Gessler M (2012) Target gene analysis by microarrays and chromatin immunoprecipitation identifies HEY proteins as highly redundant bHLH repressors. PLoS Genet 8:e1002728. CrossRef Medline

Helms AW, Abney AL, Ben-Arie N, Zoghbi HY, Johnson JE (2000) Autoregulation and multiple enhancers control Math1 expression in the developing nervous system. Development 127:1185-1196. Medline

Henrique D, Adam J, Myat A, Chitnis A, Lewis J, Ish-Horowicz D (1995) Expression of a Delta homologue in prospective neurons in the chick. Nature 375:787-790. CrossRef Medline

Huh SH, Jones J, Warchol ME, Ornitz DM (2012) Differentiation of the lateral compartment of the cochlea requires a temporally restricted FGF20 signal. PLoS Biol 10:e1001231. CrossRef Medline

Ishibashi M, Moriyoshi K, Sasai Y, Shiota K, Nakanishi S, Kageyama R (1994) Persistent expression of helix-loop-helix factor HES-1 prevents mammalian neural differentiation in the central nervous system. EMBO J 13: 1799-1805. Medline

Jones JM, Montcouquiol M, Dabdoub A, Woods C, Kelley MW (2006) Inhibitors of differentiation and DNA binding (Ids) regulate Math1 and hair cell formation during the development of the organ of Corti. J Neurosci 26:550-558. CrossRef Medline

Kageyama R, Ohtsuka T, Kobayashi T (2008) Roles of Hes genes in neural development. Dev Growth Differ 50 [Suppl 1]:S97-S103.

Kiernan AE, Pelling AL, Leung KK, Tang AS, Bell DM, Tease C, Lovell-Badge $\mathrm{R}$, Steel KP, Cheah KS (2005) Sox2 is required for sensory organ development in the mammalian inner ear. Nature 434:1031-1035. CrossRef Medline

Kopan R, Ilagan MX (2009) The canonical Notch signaling pathway: unfolding the activation mechanism. Cell 137:216-233. CrossRef Medline

Lee YS, Liu F, Segil N (2006) A morphogenetic wave of p27Kip1 transcription directs cell cycle exit during organ of Corti development. Development 133:2817-2826. CrossRef Medline

Li S, Mark S, Radde-Gallwitz K, Schlisner R, Chin MT, Chen P (2008) Hey2 functions in parallel with Hes1 and Hes5 for mammalian auditory sensory organ development. BMC Dev Biol 8:20. CrossRef Medline

Liu Z, Owen T, Zhang L, Zuo J (2010) Dynamic expression pattern of Sonic hedgehog in developing cochlear spiral ganglion neurons. Dev Dyn 239: 1674-1683. CrossRef Medline

Lumpkin EA, Collisson T, Parab P, Omer-Abdalla A, Haeberle H, Chen P, Doetzlhofer A, White P, Groves A, Segil N, Johnson JE (2003) Math1driven GFP expression in the developing nervous system of transgenic mice. Gene Expr Patterns 3:389-395. CrossRef Medline

Maier MM, Gessler M (2000) Comparative analysis of the human and mouse Heyl promoter: Hey genes are new Notch target genes. Biochem Biophys Res Commun 275:652-660. CrossRef Medline

Mohammadi M, McMahon G, Sun L, Tang C, Hirth P, Yeh BK, Hubbard SR, Schlessinger J (1997) Structures of the tyrosine kinase domain of fibroblast growth factor receptor in complex with inhibitors. Science 276:955960. CrossRef Medline

Montcouquiol M, Kelley MW (2003) Planar and vertical signals control cellular differentiation and patterning in the mammalian cochlea. J Neurosci 23:9469-9478. Medline

Murata J, Ohtsuka T, Tokunaga A, Nishiike S, Inohara H, Okano H, Kageyama R (2009) Notch-Hesl pathway contributes to the cochlear prosensory formation potentially through the transcriptional downregulation of p27Kip1. J Neurosci Res 87:3521-3534. CrossRef Medline

Narimatsu M, Bose R, Pye M, Zhang L, Miller B, Ching P, Sakuma R, Luga V,
Roncari L, Attisano L, Wrana JL (2009) Regulation of planar cell polarity by Smurf ubiquitin ligases. Cell 137:295-307. CrossRef Medline

Ohyama T, Groves AK (2004) Generation of Pax2-Cre mice by modification of a Pax2 bacterial artificial chromosome. Genesis 38:195-199. CrossRef Medline

Radde-Gallwitz K, Pan L, Gan L, Lin X, Segil N, Chen P (2004) Expression of Islet1 marks the sensory and neuronal lineages in the mammalian inner ear. J Comp Neurol 477:412-421. CrossRef Medline

Ruben RJ (1967) Development of the inner ear of the mouse: a radioautographic study of terminal mitoses. Acta Otolaryngol Suppl 220:221-244. Medline

Sakamoto M, Hirata H, Ohtsuka T, Bessho Y, Kageyama R (2003) The basic helix-loop-helix genes Hesr1/Heyl and Hesr2/Hey2 regulate maintenance of neural precursor cells in the brain. J Biol Chem 278:4480844815. CrossRef Medline

Salic A, Mitchison TJ (2008) A chemical method for fast and sensitive detection of DNA synthesis in vivo. Proc Natl Acad Sci U S A 105:24152420. CrossRef Medline

Schmittgen TD, Livak KJ (2008) Analyzing real-time PCR data by the comparative C(T) method. Nat Protoc 3:1101-1108. CrossRef Medline

Sher AE (1971) The embryonic and postnatal development of the inner ear of the mouse. Acta Otolaryngol Suppl 285:1-77. Medline

Shroyer NF, Helmrath MA, Wang VY, Antalffy B, Henning SJ, Zoghbi HY (2007) Intestine-specific ablation of mouse atonal homolog 1 (Math1) reveals a role in cellular homeostasis. Gastroenterology 132:2478-2488. CrossRef Medline

Takanaga H, Tsuchida-Straeten N, Nishide K, Watanabe A, Aburatani H, Kondo T (2009) Gli2 is a novel regulator of sox2 expression in telencephalic neuroepithelial cells. Stem Cells 27:165-174. CrossRef Medline

Takebayashi S, Yamamoto N, Yabe D, Fukuda H, Kojima K, Ito J, Honjo T (2007) Multiple roles of Notch signaling in cochlear development. Dev Biol 307:165-178. CrossRef Medline

Tateya T, Imayoshi I, Tateya I, Ito J, Kageyama R (2011) Cooperative functions of Hes/Hey genes in auditory hair cell and supporting cell development. Dev Biol 352:329-340. CrossRef Medline

Tateya T, Imayoshi I, Tateya I, Hamaguchi K, Torii H, Ito J, Kageyama R (2013) Hedgehog signaling regulates prosensory cell properties during the basal-to-apical wave of hair cell differentiation in the mammalian cochlea. Development 140:3848-3857. CrossRef Medline

Vokes SA, Ji H, McCuine S, Tenzen T, Giles S, Zhong S, Longabaugh WJ, Davidson EH, Wong WH, McMahon AP (2007) Genomic characterization of Gli-activator targets in sonic hedgehog-mediated neural patterning. Development 134:1977-1989. CrossRef Medline

von Bartheld CS, Patterson SL, Heuer JG, Wheeler EF, Bothwell M, Rubel EW (1991) Expression of nerve growth factor (NGF) receptors in the developing inner ear of chick and rat. Development 113:455-470. Medline

Wall DS, Mears AJ, McNeill B, Mazerolle C, Thurig S, Wang Y, Kageyama R, Wallace VA (2009) Progenitor cell proliferation in the retina is dependent on Notch-independent Sonic hedgehog/Hes1 activity. J Cell Biol 184:101-112. CrossRef Medline

Wang J, Mark S, Zhang X, Qian D, Yoo SJ, Radde-Gallwitz K, Zhang Y, Lin X, Collazo A, Wynshaw-Boris A, Chen P (2005) Regulation of polarized extension and planar cell polarity in the cochlea by the vertebrate PCP pathway. Nat Genet 37:980-985. CrossRef Medline

Woods C, Montcouquiol M, Kelley MW (2004) Math1 regulates development of the sensory epithelium in the mammalian cochlea. Nat Neurosci 7:1310-1318. CrossRef Medline

Wu SM, Tan KS, Chen H, Beh TT, Yeo HC, Ng SK, Wei S, Lee DY, Choo AB, Chan KK (2012) Enhanced production of neuroprogenitors, dopaminergic neurons, and identification of target genes by overexpression of sonic hedgehog in human embryonic stem cells. Stem Cells Dev 21:729 741. CrossRef Medline

Yamamoto N, Chang W, Kelley MW (2011) Rbpj regulates development of prosensory cells in the mammalian inner ear. Dev Biol 353:367-379. CrossRef Medline

Yang H, Xie X, Deng M, Chen X, Gan L (2010) Generation and characterization of Atoh1-Cre knock-in mouse line. Genesis 48:407-413. CrossRef Medline 